Supporting Information for

\title{
Heterogeneous Isomerization for Stereoselective Alkyne Hydrogenation to trans-Alkene Mediated by Frustrated Hydrogen Atoms
}

\author{
Weijie Zhang, ${ }^{\ddagger}$ Ruixuan Qin, ${ }^{\ddagger}$ Gang Fu, Nanfeng Zheng*
}

State Key Laboratory for Physical Chemistry of Solid Surfaces, Collaborative Innovation Center of Chemistry for Energy Materials, and National \& Local Joint Engineering Research Center for Preparation Technology of Nanomaterials, College of Chemistry and Chemical Engineering, Xiamen University, Xiamen, 361005, China

* The authors contributed equally to this work.

* Correspondence to: nfzheng@xmu.edu.cn 


\section{Materials and Methods}

$\underline{\text { Materials }}$

Pd (II) acetylacetonate, $\mathrm{Rh}$ (III) acetylacetonate, $\mathrm{Na}_{2} \mathrm{~S}$, phenylpropyne, terminal alkenes, were purchased from Sigma-Aldrich. Ethylene glycol, ethanol, poly(vinylpyrrolidone) (PVP, MW=30,000), acetone, $N, N$-dimethylformamide (DMF), hexadecyl trimethyl ammonium bromide (CTAB) were purchased from Sinopharm Chemical Reagent Co. Ltd. (Shanghai, China). $\mathrm{H}_{2}$ (99.999\%) and $\mathrm{D}_{2}(99.999 \%)$ were purchased from Linde Gas. The water used in all experiments was ultrapure (18.2 M $\Omega$ ). All reagents were used as received without further purification.

\section{UV-Vis-near IR absorption spectra measurements}

All the UV-Vis-near IR absorption spectra of Pd nanosheets were taken on a CARY 5000 Scan UV-Vis-near IR spectrophotometer (Varian). Prior to IR test, the sample should be dried at $85^{\circ} \mathrm{C}$ for $24 \mathrm{hr}$.

\section{$\underline{\mathrm{X} \text {-ray absorption spectroscopy (XAS) measurements }}$}

The X-ray absorption spectra at the $\mathrm{Pd} \mathrm{K}$-edge and $\mathrm{Rh} \mathrm{K}$-edge was recorded at room temperature in transmission mode using ion chambers at beam line BL14W1 of the Shanghai Synchrotron Radiation Facility (SSRF), China. The station was operated with a $\mathrm{Si}(311)$ double crystal monochromator. During the measurement, the synchrotron was operated at energy of $3.5 \mathrm{GeV}$ and a current between 150-210 mA. The photon energy was calibrated with the first inflection point of Pd K-edge in Pd metal foil.

The obtained XAFS data was processed in Athena (version 0.9.26) for background, preedge line and post-edge line calibrations. Then Fourier transformed fitting was carried out in Artemis (version 0.9.26). The $\mathrm{k}^{3}$ weighting, k-range of $3-12 \AA^{-1}$ and $\mathrm{R}$ range of $1-\sim 3$ $\AA$ were used for the fitting. The four parameters, coordination number, bond length, Debye-

Waller factor and $\mathrm{E}_{0}$ shift $\left(\mathrm{CN}, \mathrm{R}, \sigma^{2}, \Delta \mathrm{E}_{0}\right)$ were fitted without anyone was fixed, constrained, or correlated.

\section{In situ FT-IR reflection spectroscopic studies}

In the FT-IR experiments, $25 \mathrm{mg}$ original Pd nanosheets or modified catalyst was first dispersed on a plate in a glass pressure cell. The cell was then charged with $\mathrm{CO}, \mathrm{H}_{2}$ or $\mathrm{D}_{2}$ to $0.1 \mathrm{MPa}$ and kept at $30^{\circ} \mathrm{C}$. After several minutes, the infrared spectra were collected. 


\section{Proton nuclear magnetic resonance $\left({ }^{1} \mathrm{H}\right.$ NMR $)$}

To probe if the hydrogen transfer could process during hydrogenation, $\mathrm{CH}_{3} \mathrm{OD}$ was used as solvent in the phenylacetylene hydrogenation reaction. The $2 \times 10^{-3} \mu \mathrm{mol} \mathrm{Pd}$ catalyst was first dispersed in $10 \mathrm{~mL} \mathrm{CH}_{3} \mathrm{OD}$ in a glass pressure vessel. The catalyst dispersion was mixed with $0.5 \mu \mathrm{mol}$ substrate by a magnetic stirring bar. The vessel was then charged with $\mathrm{H}_{2}$ to $0.1 \mathrm{MPa}$ and kept at $60{ }^{\circ} \mathrm{C}$ during stirring. The reaction was stopped after $100 \%$ conversion determined by gas chromatographic analysis. After that, the mixture was centrifuged to remove the catalyst. The supernatant was used as the sample for ${ }^{1} \mathrm{H}$ NMR. ${ }^{1} \mathrm{H}$ NMR spectra were recorded in $\mathrm{CH}_{3} \mathrm{OD}$ on a Bruker AV400 spectrometer. In turn, the vessel with $10 \mathrm{~mL} \mathrm{CH}_{3} \mathrm{OH}$ was then charged with $\mathrm{D}_{2}$ to $0.2 \mathrm{MPa}$ and kept at $60{ }^{\circ} \mathrm{C}$ during stirring. The supernatant after centrifugation was used as the sample for ${ }^{1} \mathrm{H}$ NMR.

\section{$\underline{\text { Characterization }}$}

The powder X-ray diffraction (XRD) experiments were conducted on Rigaku Ultima IV using $\mathrm{Cu} \mathrm{K \alpha}$ radiation. The operation voltage and current were $40 \mathrm{kV}$ and $30 \mathrm{~mA}$ respectively. The scanning speed was set as 10 degree/min. TEM studies were performed on a TECNAI F-30 high-resolution transmission electron microscope operating at $300 \mathrm{kV}$. The samples were prepared by dropping ethanol dispersion of samples onto 300-mesh carbon-coated copper grids and immediately evaporating the solvent. GC analyses were performed with a FuLi 9790II, equipped with a split/splitless injector, a capillary column $(\mathrm{KB}-5,30 \mathrm{~m} \times 0.32 \mathrm{~mm} \times 0.33 \mu \mathrm{m})$ and a flame ionization detector. SERS and Raman spectra were acquired using a confocal Raman system (Xplora, Horiba) using a $633 \mathrm{~nm}$ laser as the excitation light with the power around $0.15 \mathrm{~mW}$. Infrared spectra were measured with a Nicolet Avatar 360 FT-IR spectrometer. The thermogravimetric analysis (TGA) was performed on a TA SDT_Q600 analyser with a temperature ramping rate of $10{ }^{\circ} \mathrm{C} \mathrm{min}{ }^{-1}$ under a $\mathrm{N}_{2}$ atmosphere. Elemental analysis was performed on a Vario EL III(Germany). An XPS apparatus (PHI QUANTUM 2000) was applied to perform XPS measurements. 


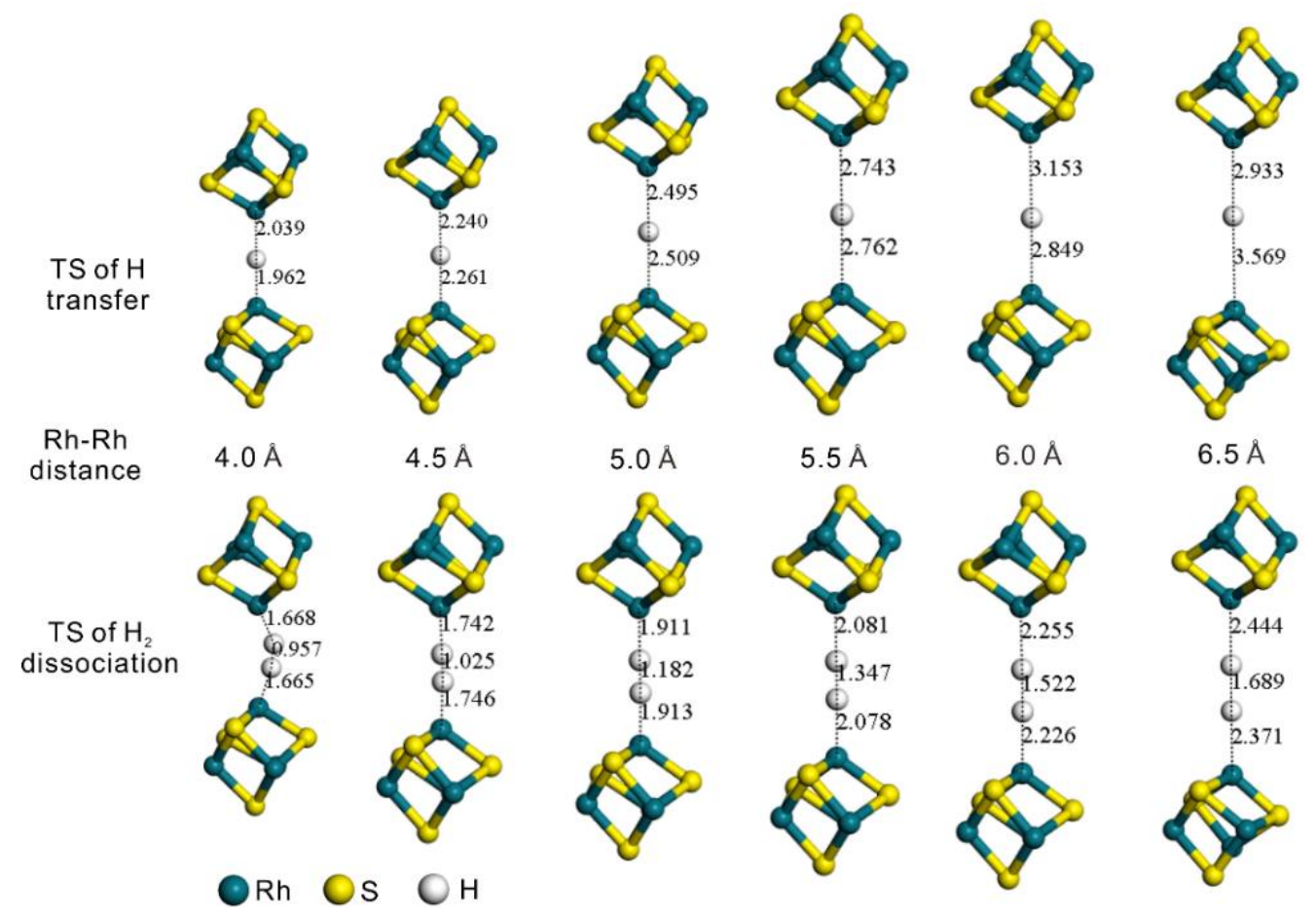

Figure S1. Structures of the transition states during $\mathrm{H}$ transfer and dissociation of $\mathrm{H}_{2}$ between the $\mathrm{Rh}$ sites in neighboring $\left[\mathrm{Rh}_{3} \mathrm{~S}_{3}\right]$ clusters.

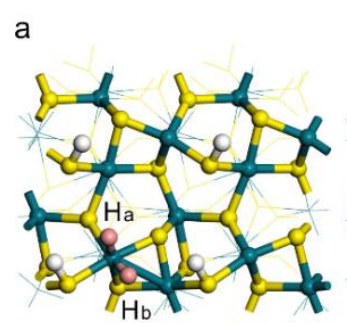

II b

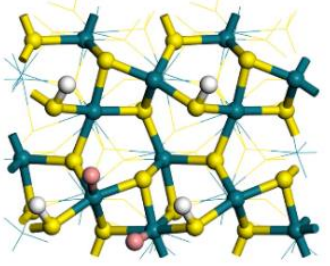

$\Delta \mathrm{E}_{2 \mathrm{H}}=0.25 \mathrm{eV}$
C

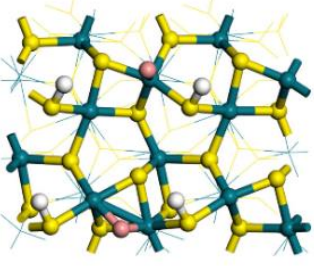

$\Delta \mathrm{E}_{2 \mathrm{H}}=0.34 \mathrm{eV}$ d

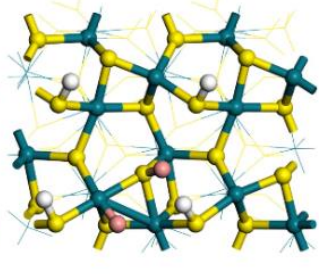

$\Delta \mathrm{E}_{2 \mathrm{H}}=0.23 \mathrm{eV}$

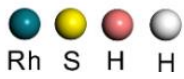

Figure S2. (a) Steady state of dissociated $\mathrm{H}_{2}$ by the surface $\mathrm{Rh}_{\mathrm{IV}}$ site (corresponding to II in Figure 1. (b) Structures and corresponding dissociative binding energy of $\mathrm{H}_{2}$ at other possible sites on $\mathrm{Rh}_{2} \mathrm{~S}_{3}(110)$. 


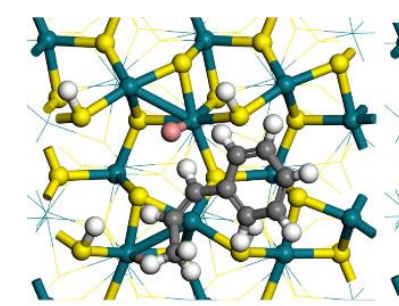

IV

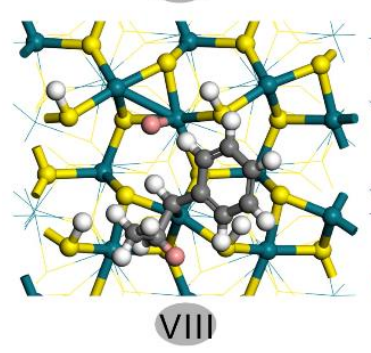

$\odot \bigcirc \odot \odot 0$

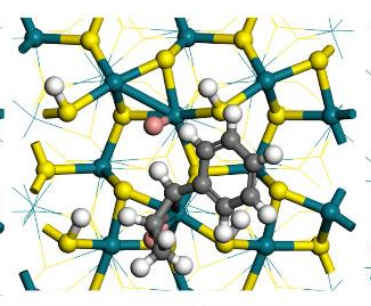

V

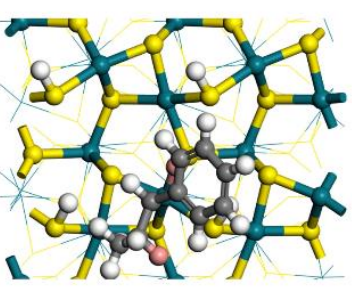

IX
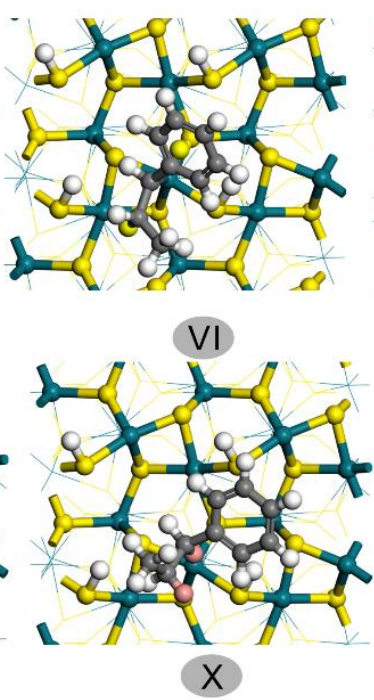

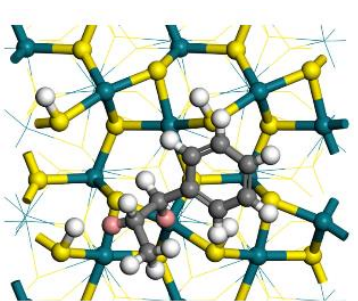

VII

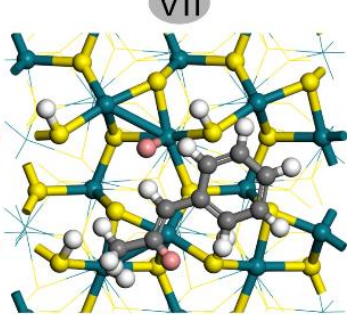

$\mathrm{XI}$ Rh S C H H

Figure S3. The top view structures of the related steady state during $\mathrm{Rh}_{2} \mathrm{~S}_{3}(110)$ catalyzed HMI of cis-1-phenyl-1-propene.

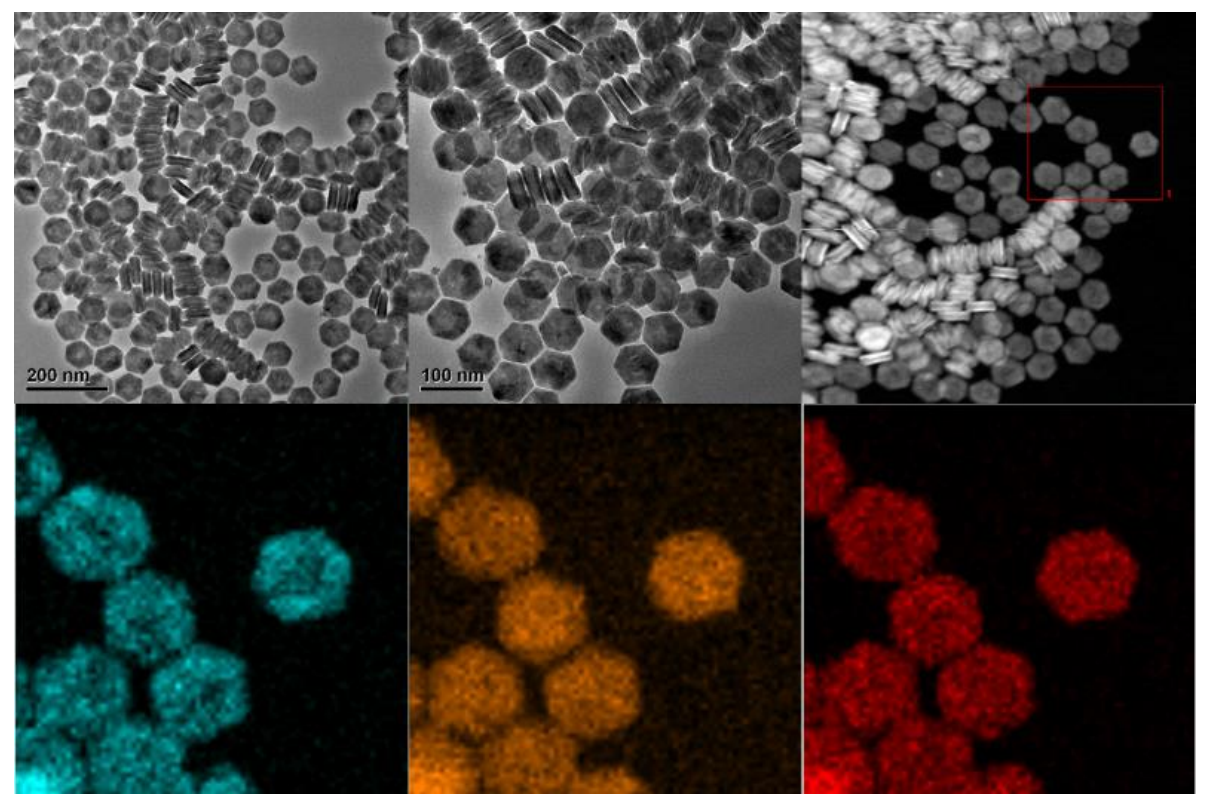

Figure S4. Transmission electron microscope (TEM) images, high angle annular dark field scanning transmission electron microscopy (HAADF-STEM) image and Energy dispersive $\mathrm{X}$-ray (EDX) mapping images of $\mathrm{Rh}_{2} \mathrm{~S}_{3} / \mathrm{Cu}_{1.94} \mathrm{~S}$. 


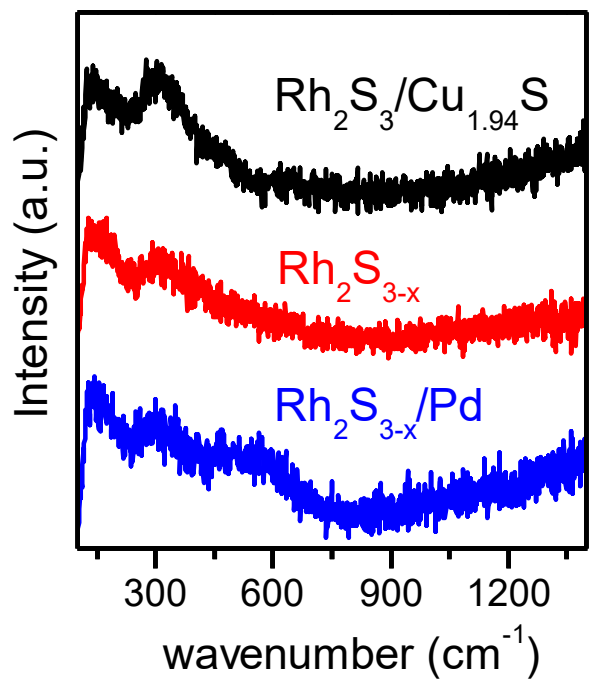

Figure S5. Raman spectra of $\mathrm{Rh}_{2} \mathrm{~S}_{3} / \mathrm{Cu}_{1.94} \mathrm{~S}, \mathrm{Rh}_{2} \mathrm{~S}_{3-\mathrm{x}}$ and $\mathrm{Rh}_{2} \mathrm{~S}_{3-\mathrm{x}} / \mathrm{Pd}$.

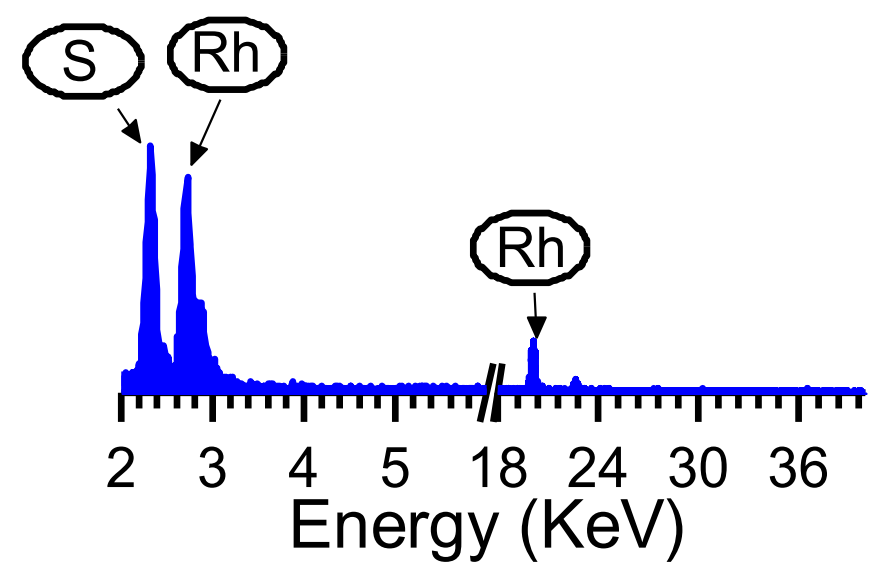

Figure S6. Energy dispersive X-ray $(E D X)$ of $\mathrm{Rh}_{2} \mathrm{~S}_{3-\mathrm{x}} .(\mathrm{Rh} / \mathrm{S} \approx 56 / 44)$ 


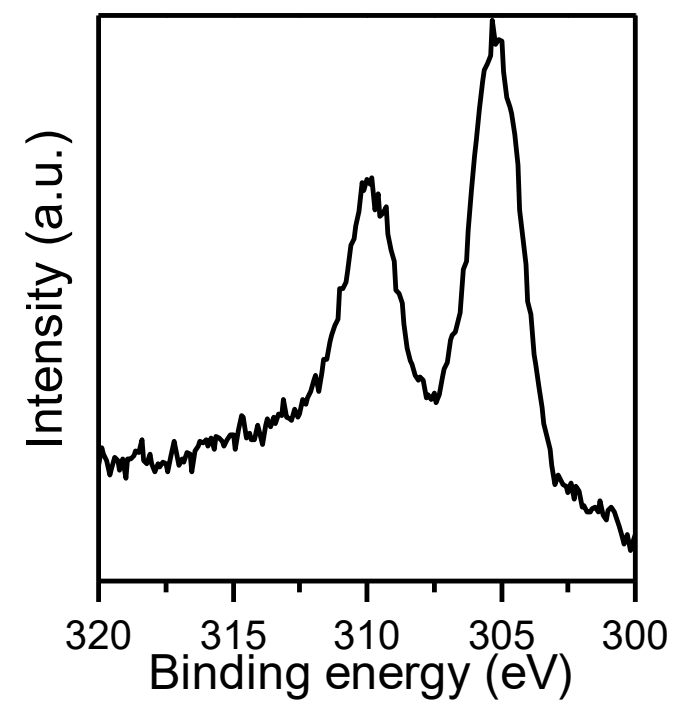

Figure S7. XPS spectra of the $R h_{2} S_{3-x}$. The binding energy region of $R h 3 d_{3 / 2}$ and $R h 3 d_{5 / 2}$ electrons indicated the presence of high-valance $\mathrm{Rh}$ species.

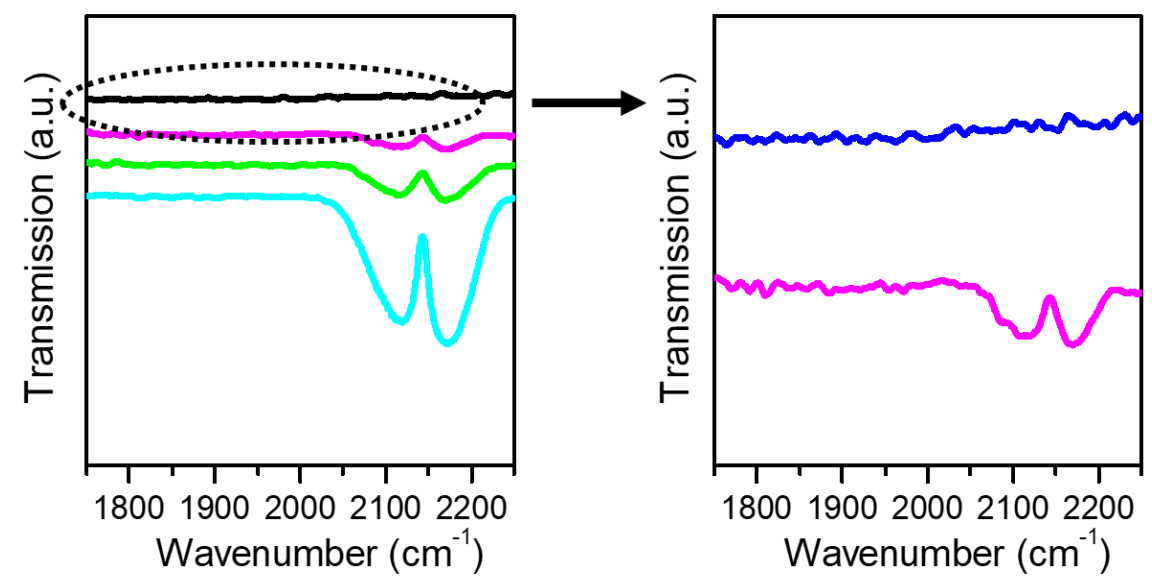

Figure S8. In-situ DRIFTS spectra for $\mathrm{CO}$ adsorbed $\mathrm{Rh}_{2} \mathrm{~S}_{3-\mathrm{x}} / \mathrm{Cu}_{1.94} \mathrm{~S}$. 


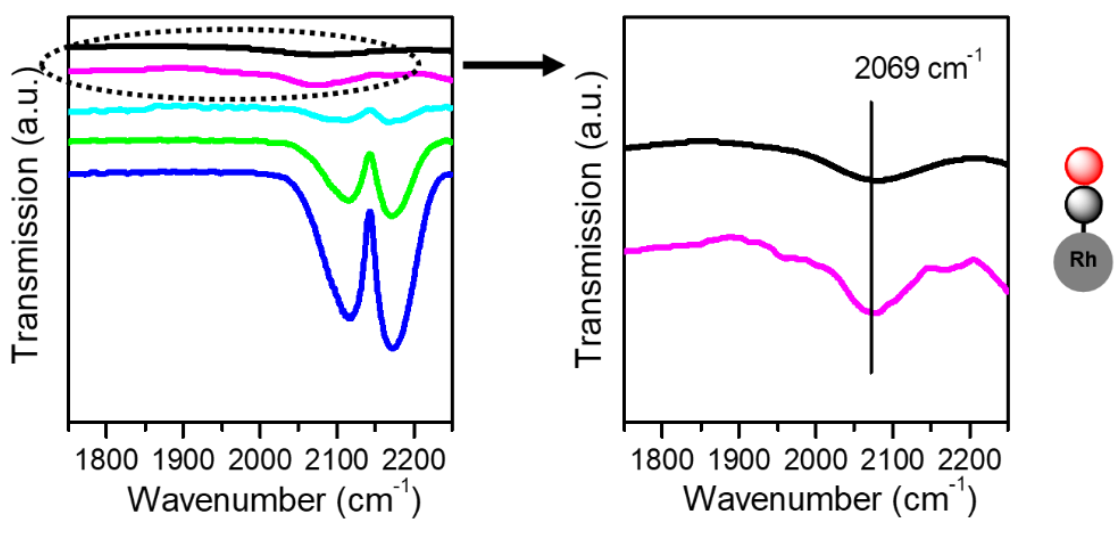

Figure S9. In-situ DRIFTS spectra for $\mathrm{CO}$ adsorbed $\mathrm{Rh}_{2} \mathrm{~S}_{3-\mathrm{x}}$.

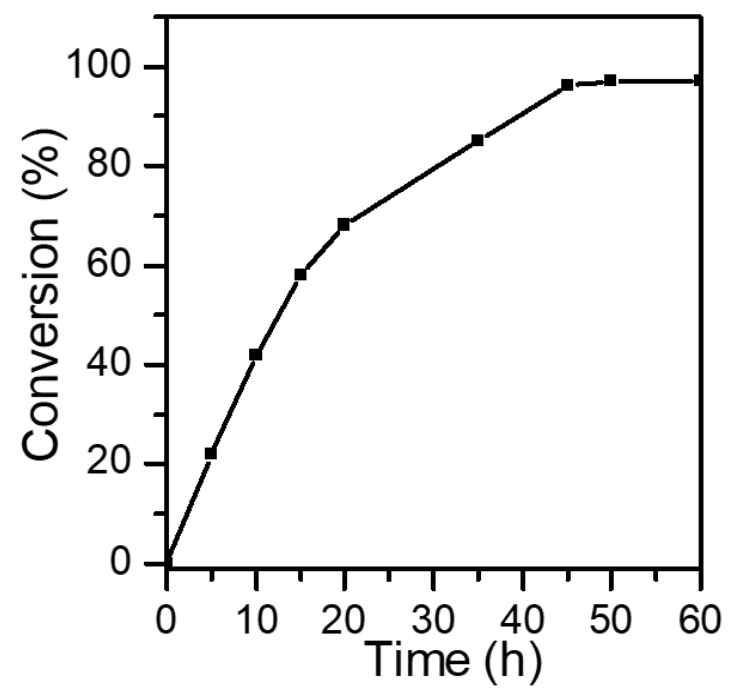

Figure S10. Isomerization of cis-stilbene to trans-stilbene catalyzed by $\mathrm{Rh}_{2} \mathrm{~S}_{3-\mathrm{x}}$. 


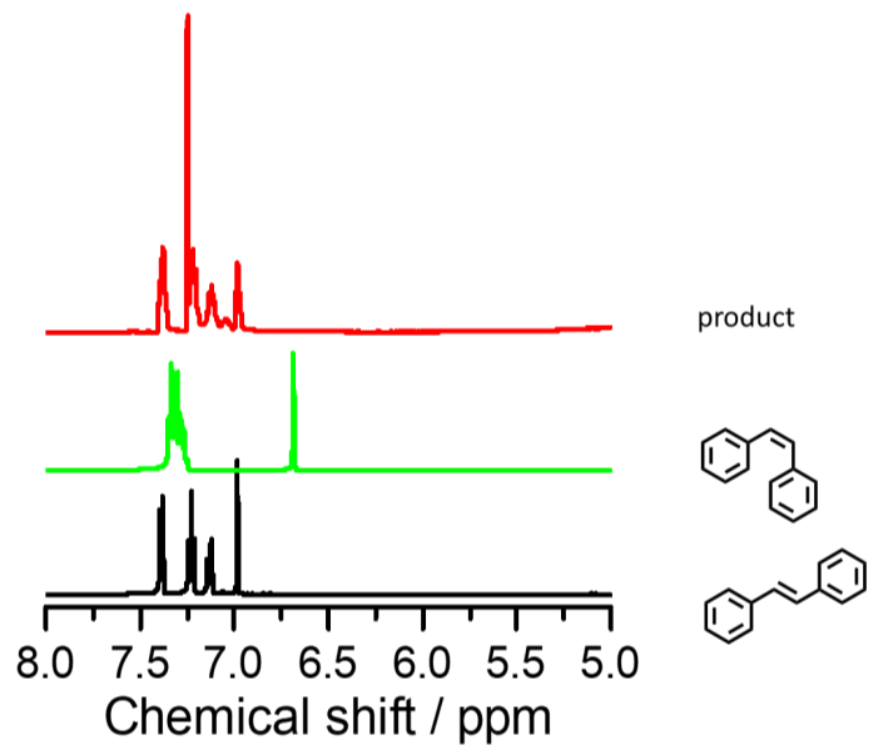

Figure S11. Schematic diagram of ${ }^{1} \mathrm{H}$ NMR data for the products of cis-stilbene isomerization carried out by using $\mathrm{Rh}_{2} \mathrm{~S}_{3-\mathrm{x}}$ as catalyst.

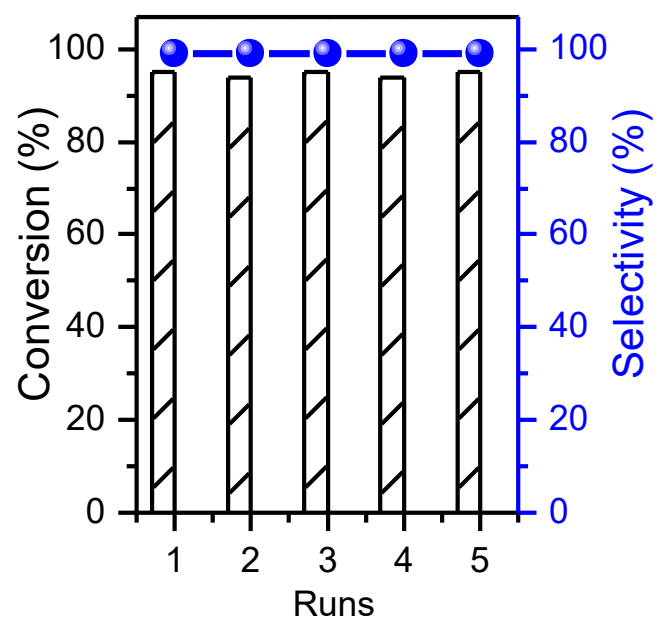

Figure S12. Assessment of the reusability of $\mathrm{Rh}_{2} \mathrm{~S}_{3-\mathrm{x}}$ in catalyzing the isomerization reaction. The reusability tests were carried out under identical conditions. 

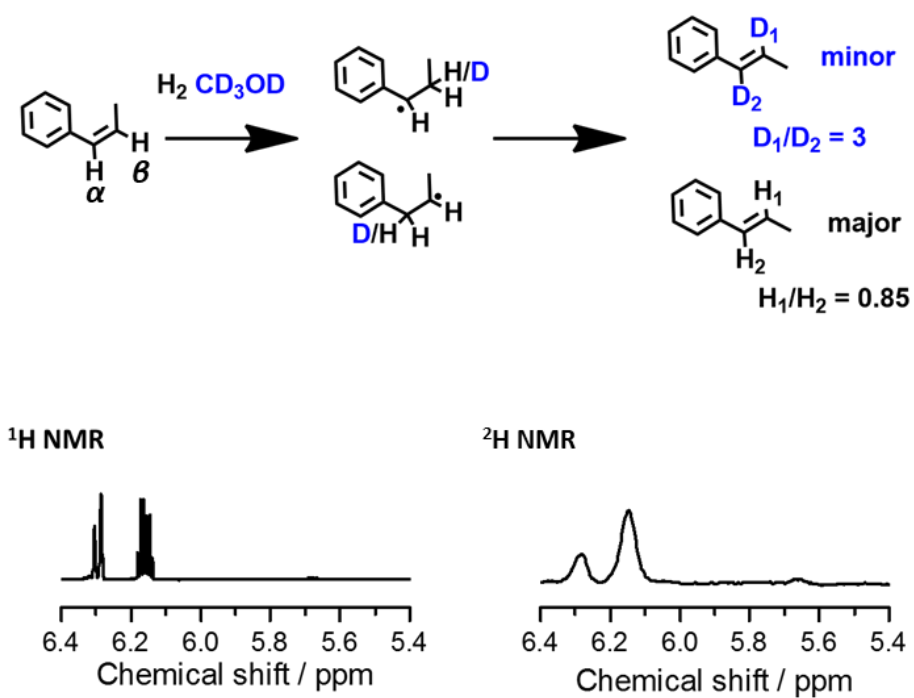

${ }^{2} \mathrm{H}$ NMR

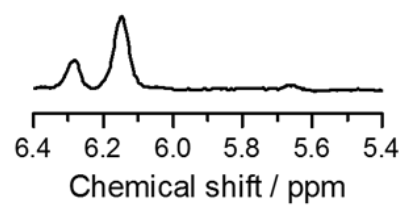

Figure S13. Schematic diagram of deuterium labeling experiments and ${ }^{1} \mathrm{H} N M R$ and ${ }^{2} \mathrm{H}$ NMR data for the products of 1-phenyl-1-propene isomerization carried out by using $\mathrm{Rh}_{2} \mathrm{~S}_{3-\mathrm{x}}$ and $\mathrm{H}_{2}$ in $\mathrm{CD}_{3} \mathrm{OD}$ as the solvent.

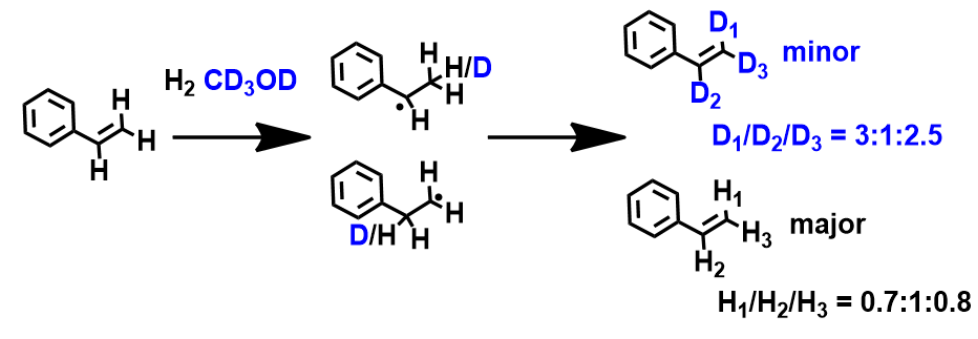

${ }^{1}$ H NMR

${ }^{2}$ H NMR
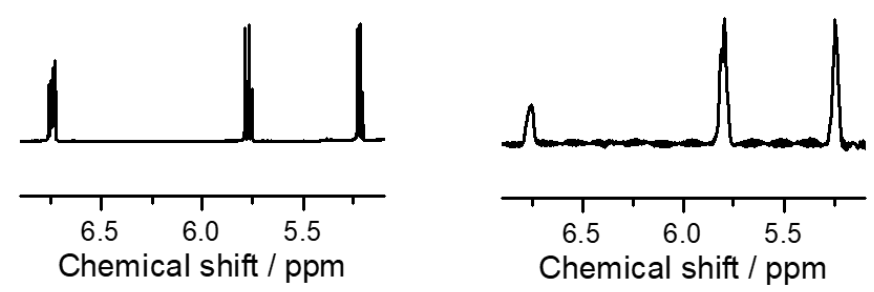

Figure S14. Schematic diagram of deuterium labeling experiments and ${ }^{1} \mathrm{H} N M R$ and ${ }^{2} \mathrm{H}$ NMR data for the styrene substrate carried out by using $\mathrm{Rh}_{2} \mathrm{~S}_{3-\mathrm{x}}$ and $\mathrm{H}_{2}$ in $\mathrm{CD}_{3} \mathrm{OD}$ as the solvent. 


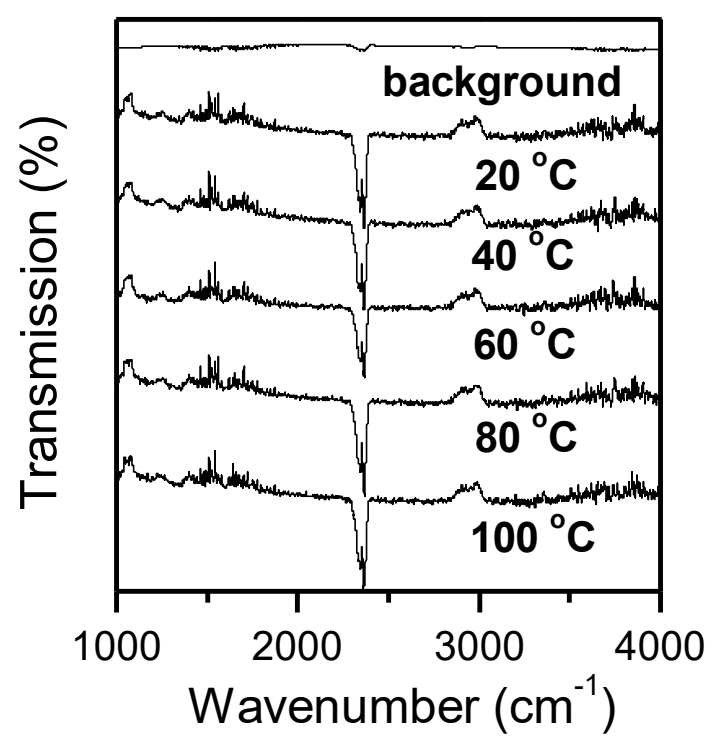

Figure S15. In-situ DRIFTS for $\mathrm{Rh}_{2} \mathrm{~S}_{3} / \mathrm{Cu}_{1.94} \mathrm{~S}$ treated with $\mathrm{D}_{2}$.

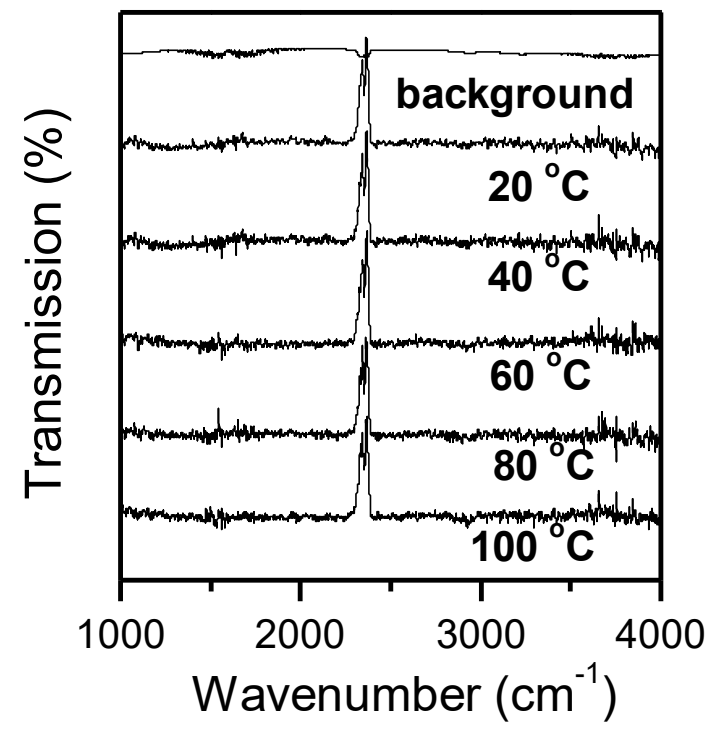

Figure S16. In-situ DRIFTS for $\mathrm{Rh}_{2} \mathrm{~S}_{3-\mathrm{x}}$ treated with $\mathrm{D}_{2}$. 


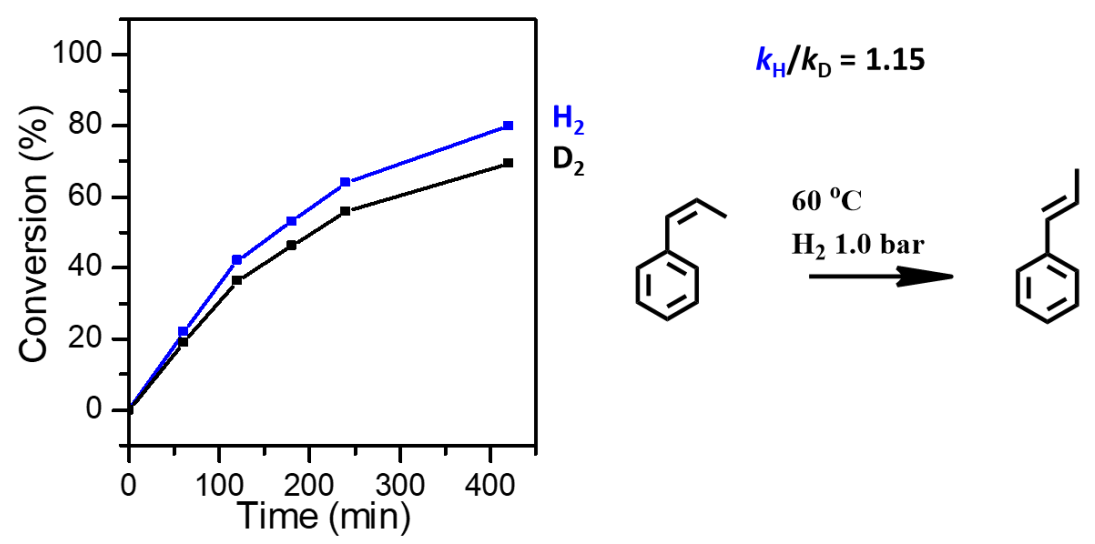

Figure S17. The kinetic isotope effect (KIE) with the use of $\mathrm{H}_{2}$ and $\mathrm{D}_{2}$ in HMI of 1-phenyl1-propene. Note: The fundamental process in the hydrogen mediated isomerization in different from that in the catalytic hydrogenation. As far as we are aware, limited effort has been directed towards the evaluation of kinetic isotope effect for the hydrogen mediated isomerization reaction. The typical rate-determining $\mathrm{C}-\mathrm{H}$ cleavage step was not related to the $\mathrm{H}_{2}$ or $\mathrm{D}_{2}$ activation, and there was no hydrogen or deuterium consumption after the isomerization. As revealed by our DFT calculation, the barrier for $\mathrm{H}_{2}$ dissociation (TS3, $0.83 \mathrm{eV}$ ) on $\mathrm{Rh}_{2} \mathrm{~S}_{3-\mathrm{x}}$ was higher than the insertion (TS4, $0.19 \mathrm{eV}$ ) and elimination (TS8, $0.29 \mathrm{eV}$ ) of $\mathrm{H}$ during isomerization. In our previous report, the inverse isotopic effect is associated with the rate-determining heterolytically dissociation of $\mathrm{H}_{2}$ into $\mathrm{Ru}-\mathrm{H}^{\delta-}$ and -O$\mathrm{H}^{\delta+}$ over atomically dispersed $\mathrm{Ru} .{ }^{9}$ On the other hand, the typical secondary isotopic effect was predicted in the homolytically dissociation of $\mathrm{H}_{2}$ on $\mathrm{Ru}(0001)$, which can be understood by the higher bond energy of $\mathrm{H}-\mathrm{H}$ in $\mathrm{H}_{2}$ than that of metal-hydride. Similarly, for the homolytically dissociation of $\mathrm{H}_{2}$ over $\mathrm{Rh}_{2} \mathrm{~S}_{3-\mathrm{x}}$, the vibration difference $\left(\Delta(\sigma)_{\mathrm{H}-\mathrm{D}}\right)$ between $\mathrm{H}$ and $\mathrm{D}$ in hydrogen molecules should also be higher than that in the dissociated state, therefore, the secondary KIE should be observed. 


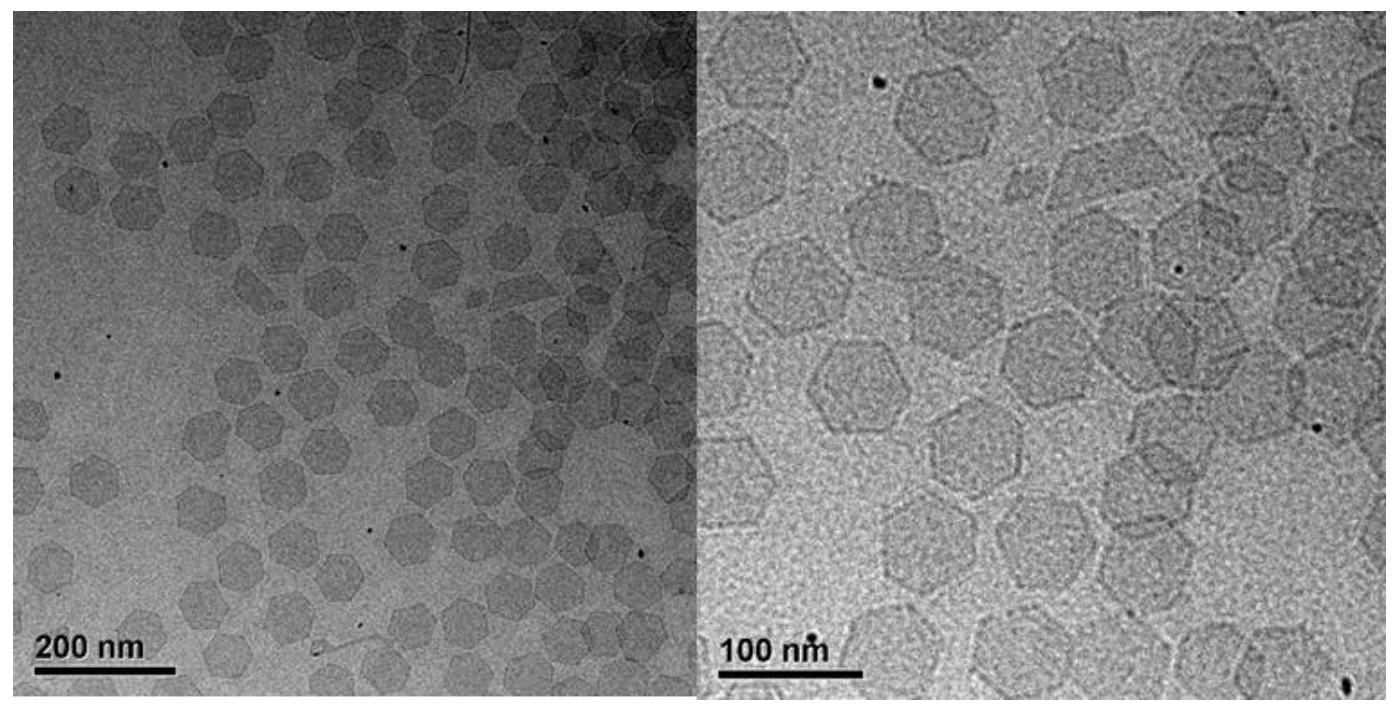

Figure S18. TEM images of $80 \mathrm{~nm}$ Pd NSs.

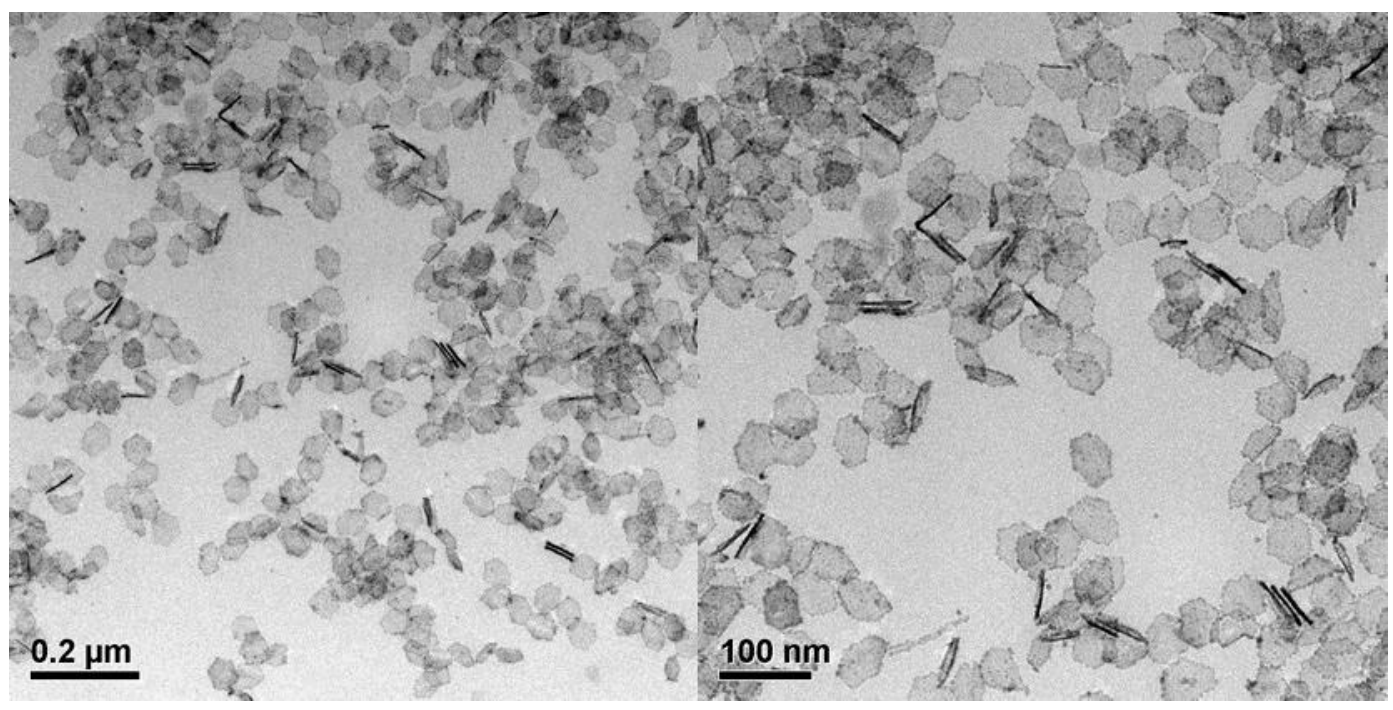

Figure S19. TEM images of $80 \mathrm{~nm} \mathrm{Rh/Pd} \mathrm{NSs.}$ 


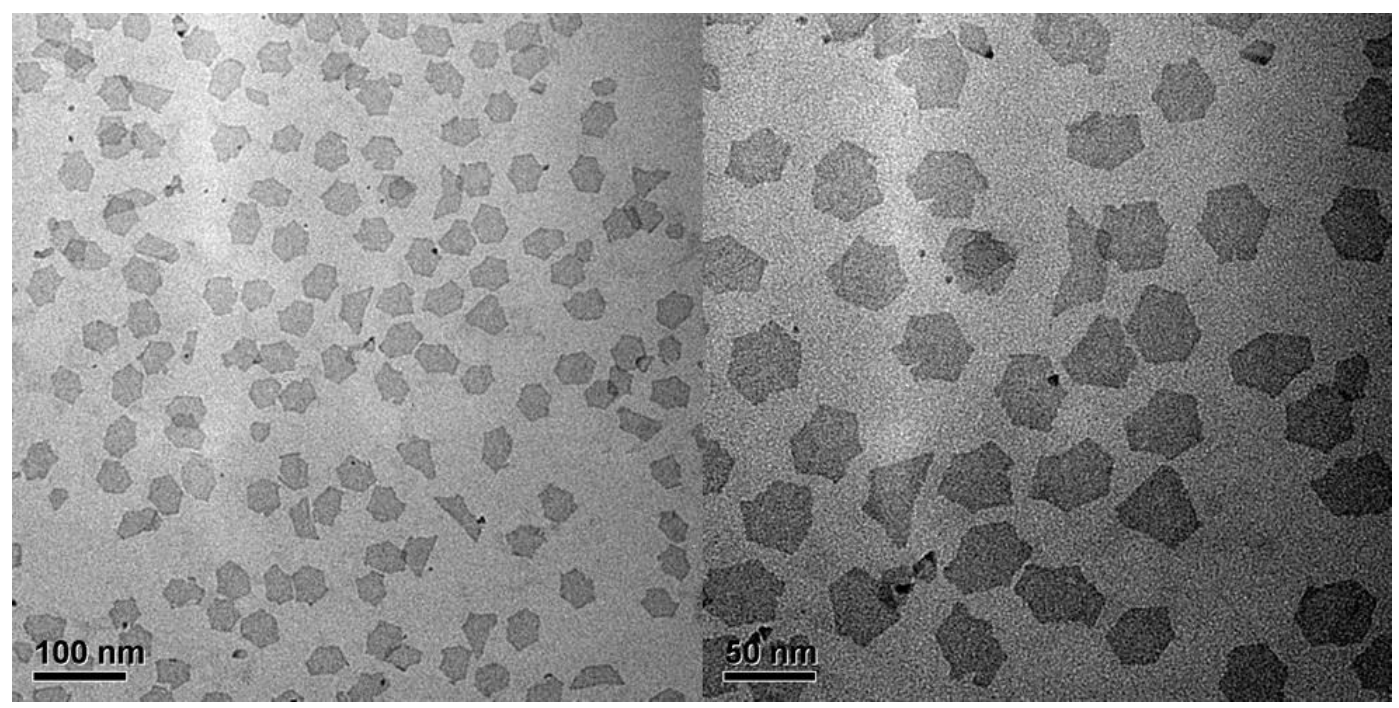

Figure S20. TEM images of $80 \mathrm{~nm}$ Rh-S/Pd NSs.

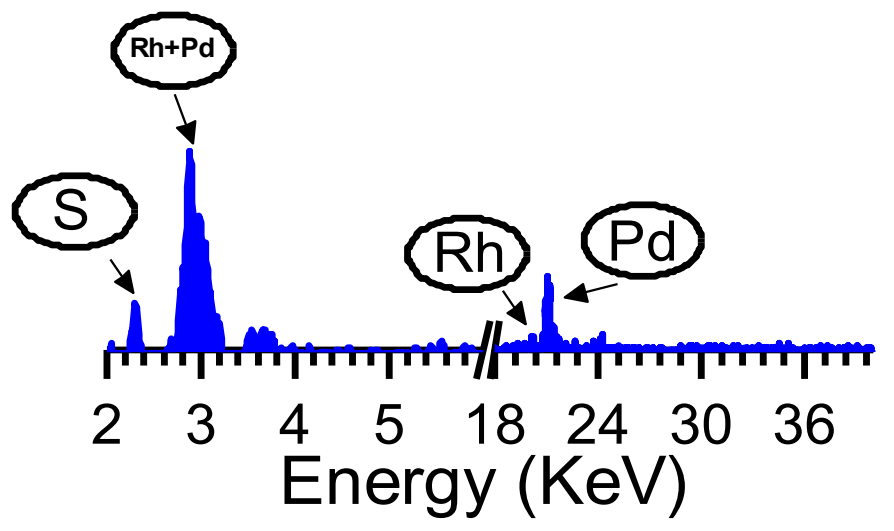

Figure S21. Energy dispersive X-ray (EDX) of Rh-S/Pd NSs. 


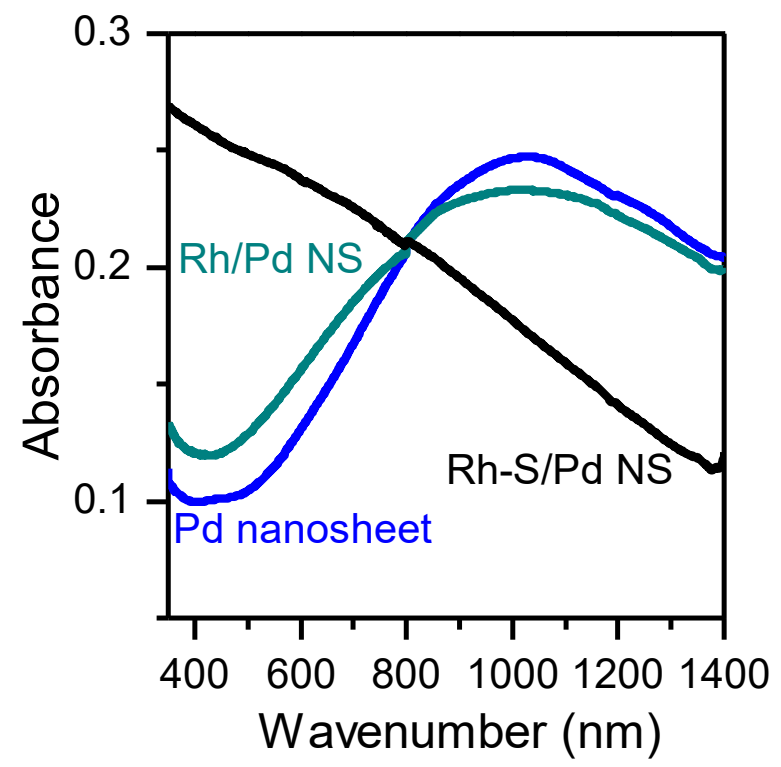

Figure S22. The UV-vis spectrum of Pd NSs, Rh/Pd NSs and Rh-S/Pd NSs.
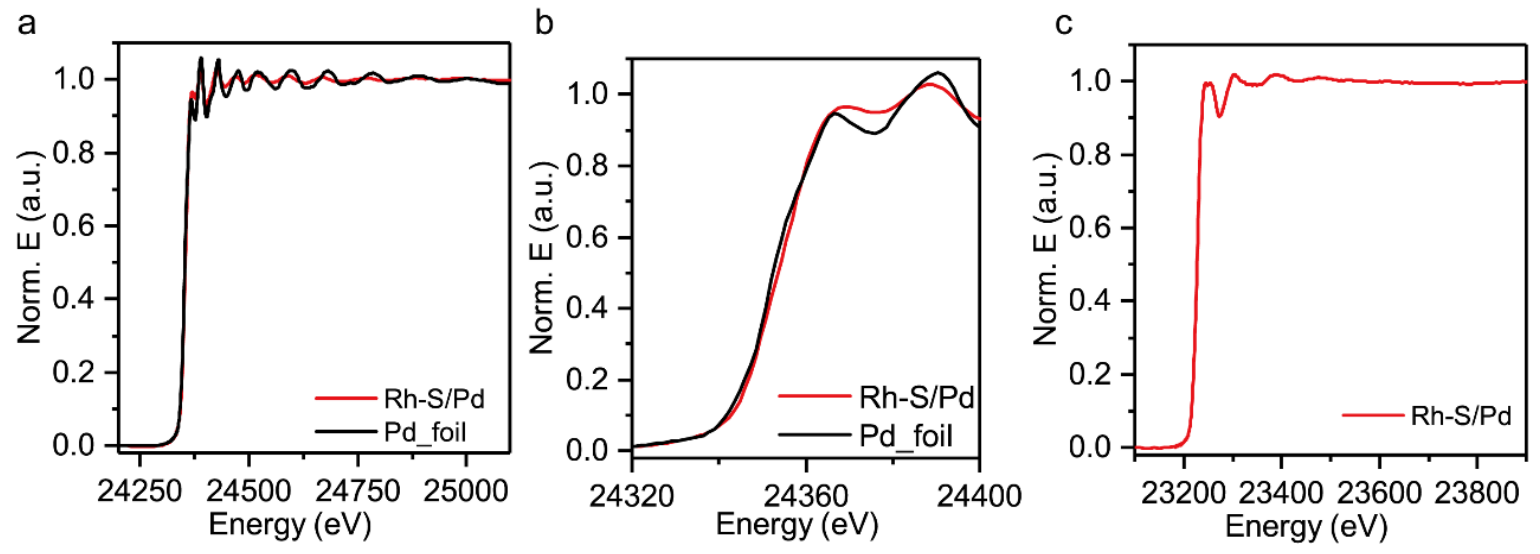

Figure S23. Pd K-edge XAS (a), XANES (b) and Rh K-edge XAS (c). 

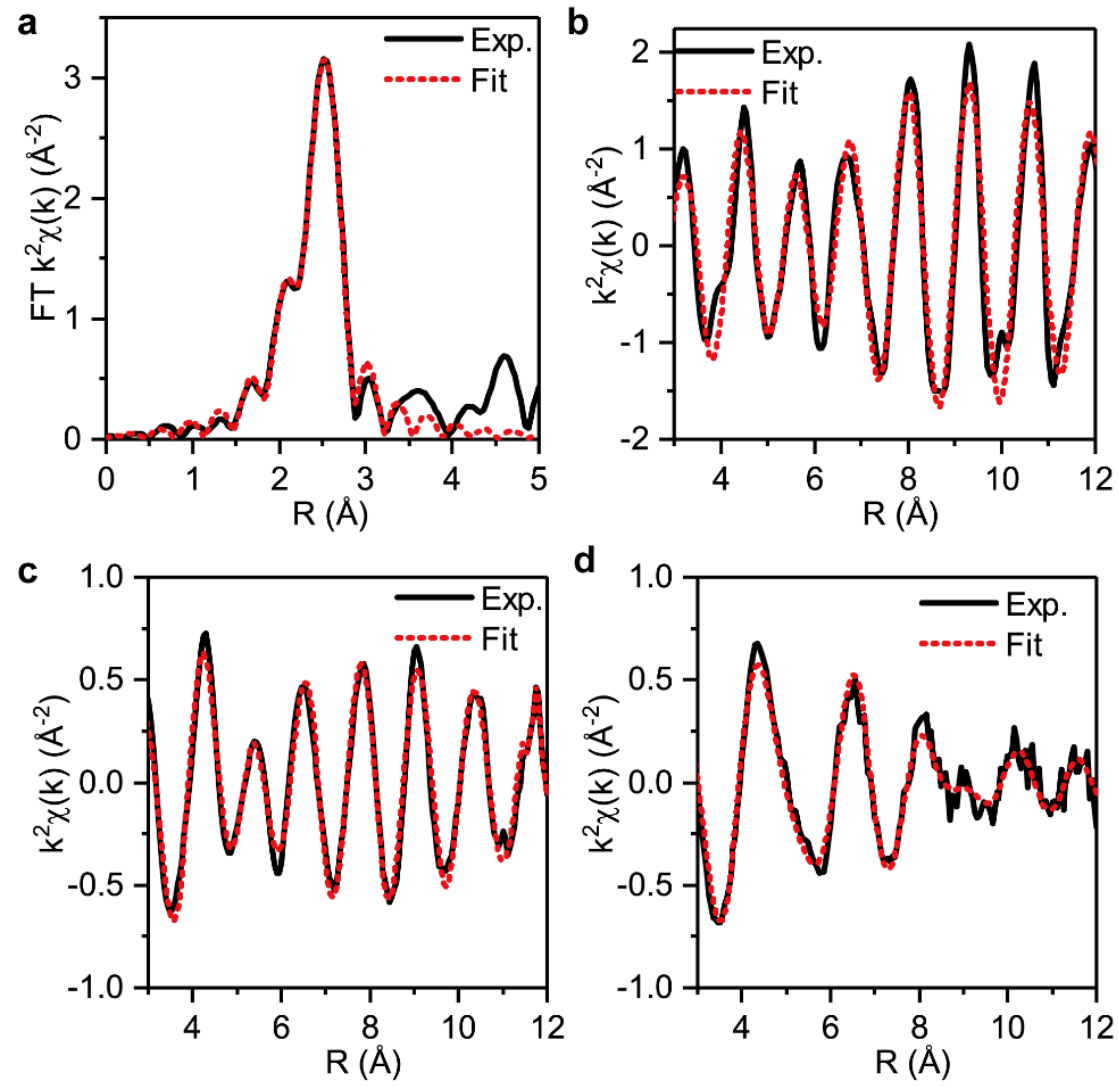

Figure S24. R-space (a) and k space (b) EAXFS fitting of Pd foil, k space EXAFS fitting of Pd (c) and Rh (d) of Rh-S/Pd NSs. 


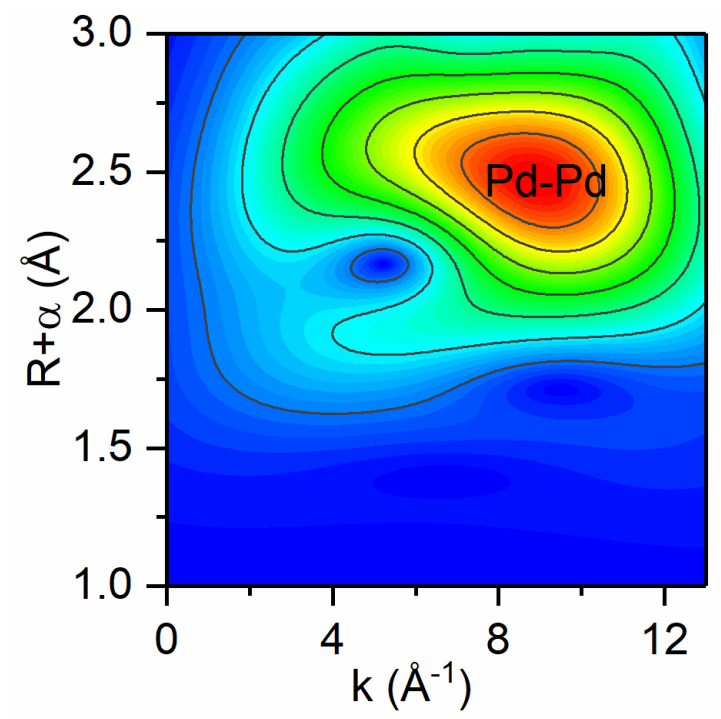

Figure S25. Wavelet transform EXAFS of Pd foil.
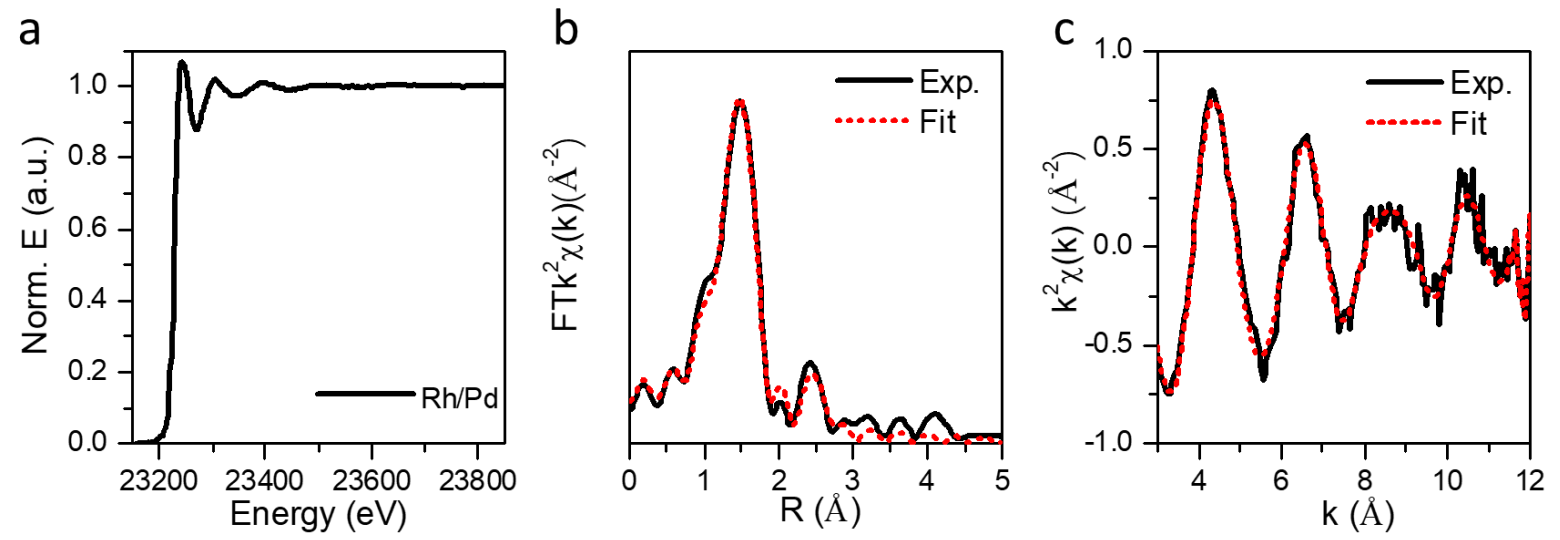

Figure S26. Rh K-edge XAS (a), R-space (b) and k space (c) of Rh/Pd NSs. 


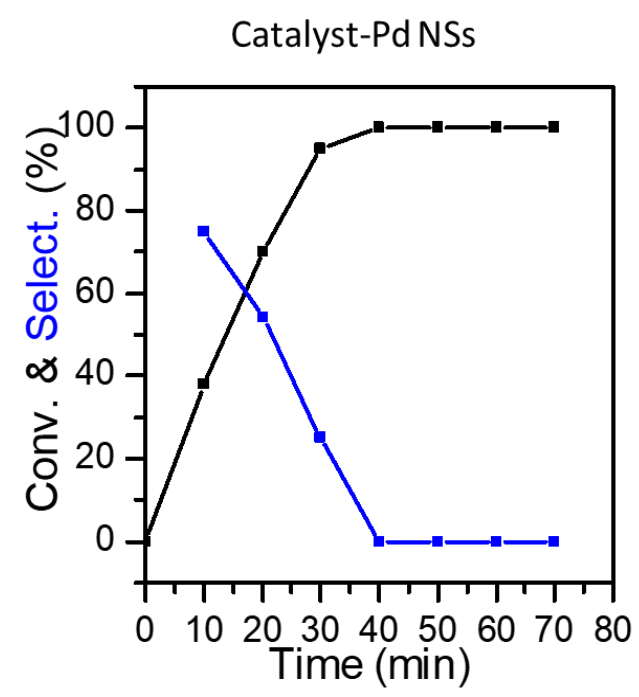

Figure S27. Hydrogenation of 1-phenyl-1-propyne catalyzed by Pd NSs.

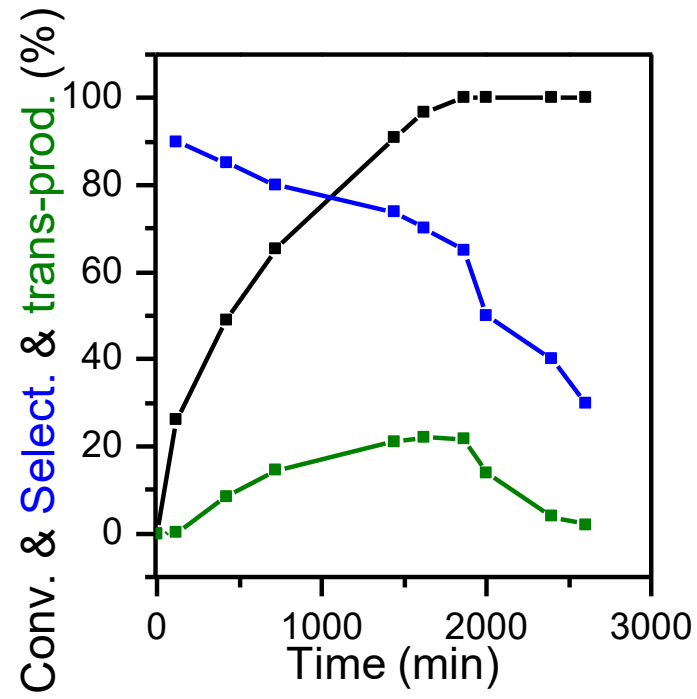

Figure S28. Hydrogenation of 1-phenyl-1-propyne to trans-product catalyzed by $\mathrm{Rh} / \mathrm{Pd}$ NSs. 


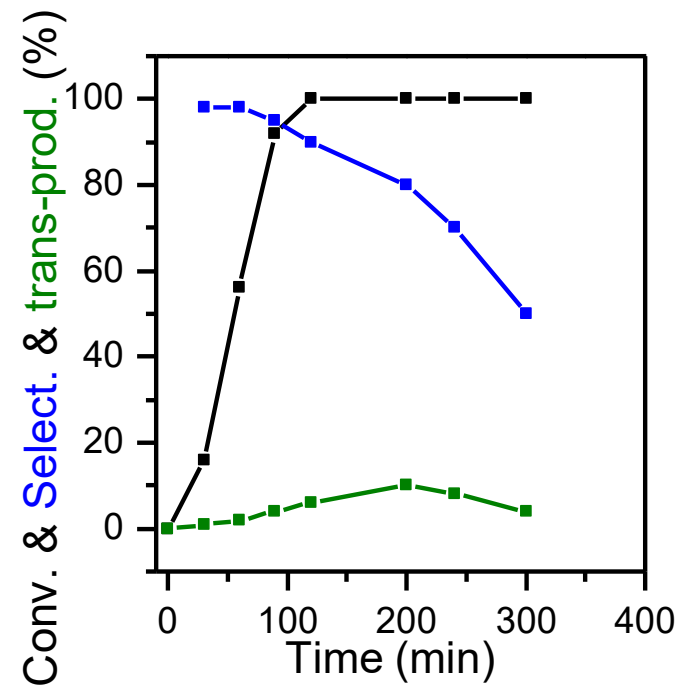

Figure S29. Hydrogenation of 1-phenyl-1-propyne to trans-product catalyzed by $\mathrm{Na}_{2} \mathrm{~S} / \mathrm{Pd}$ NSs.

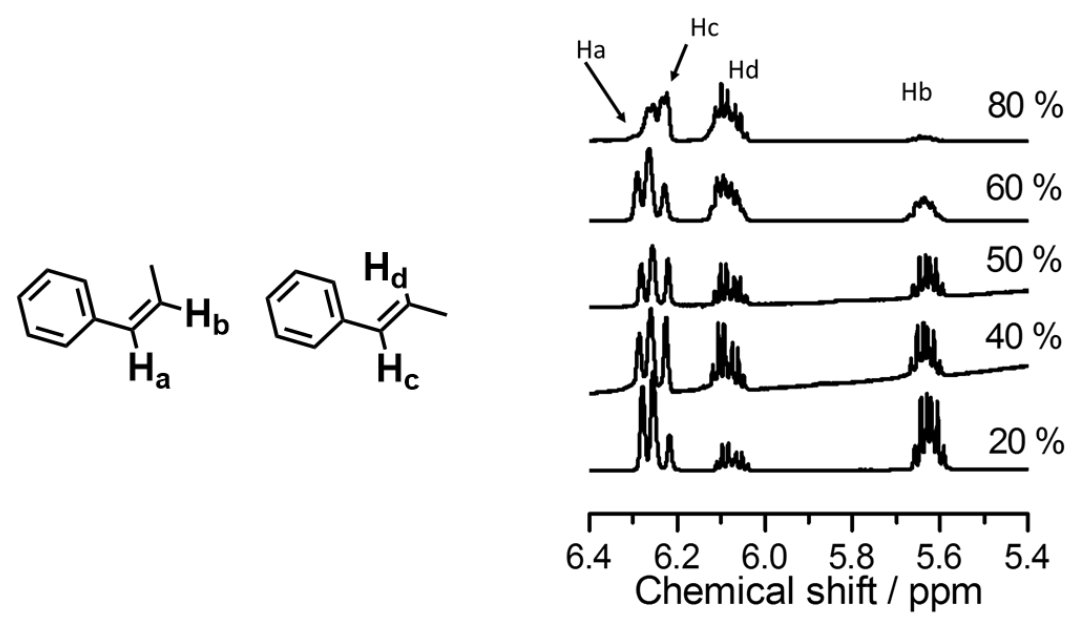

Figure S30. Hydrogenation reaction monitored by ${ }^{1} \mathrm{H}$ NMR. 


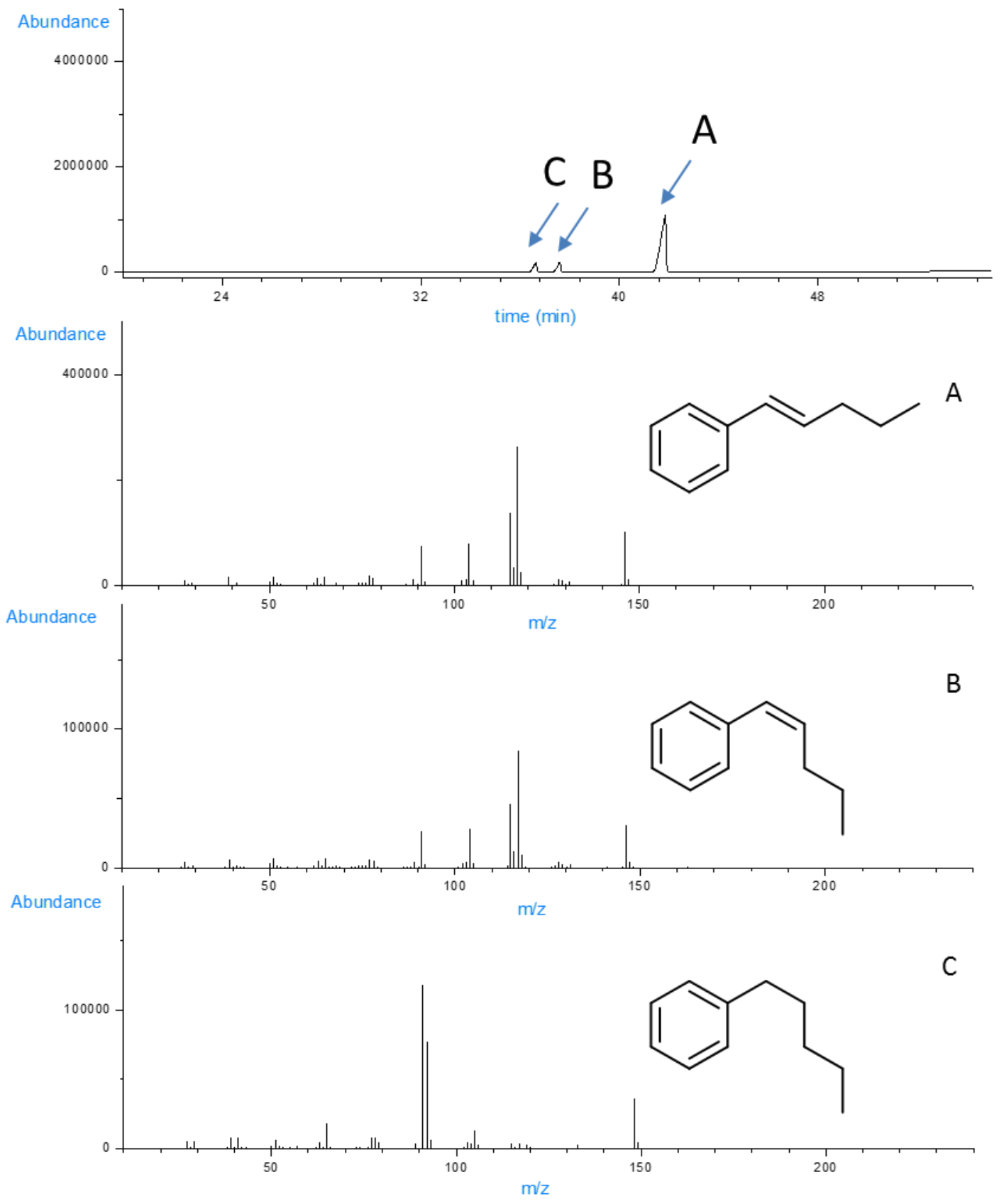

Figure S31. GC-MS data for the hydrogenation products of propyl functionalized alkyne to the corresponding trans-alkene using Rh-S/Pd NSs catalysts. 

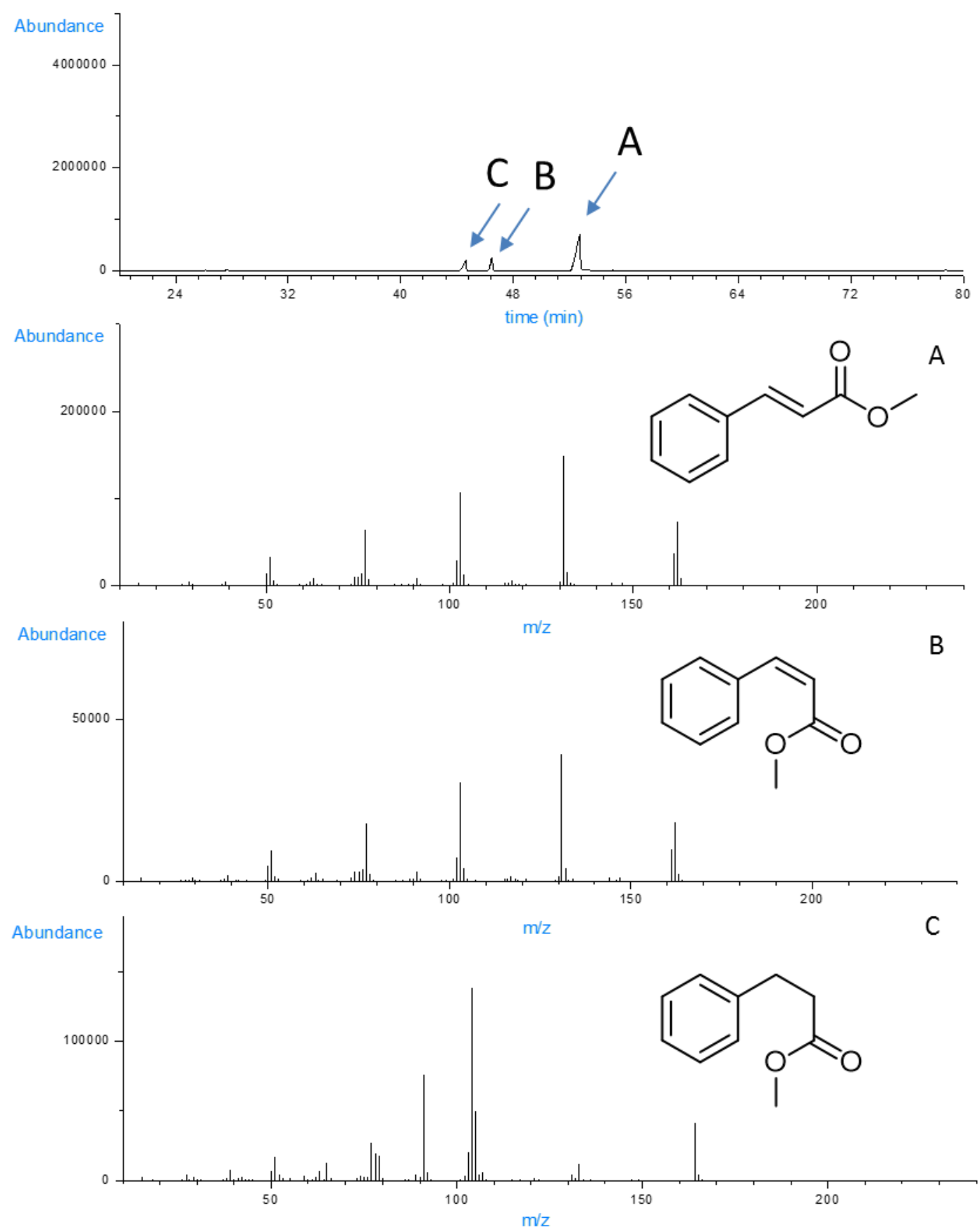

Figure S32. GC-MS data for the hydrogenation products of ester functionalized alkyne to the corresponding trans-alkene using Rh-S/Pd NSs catalysts. 


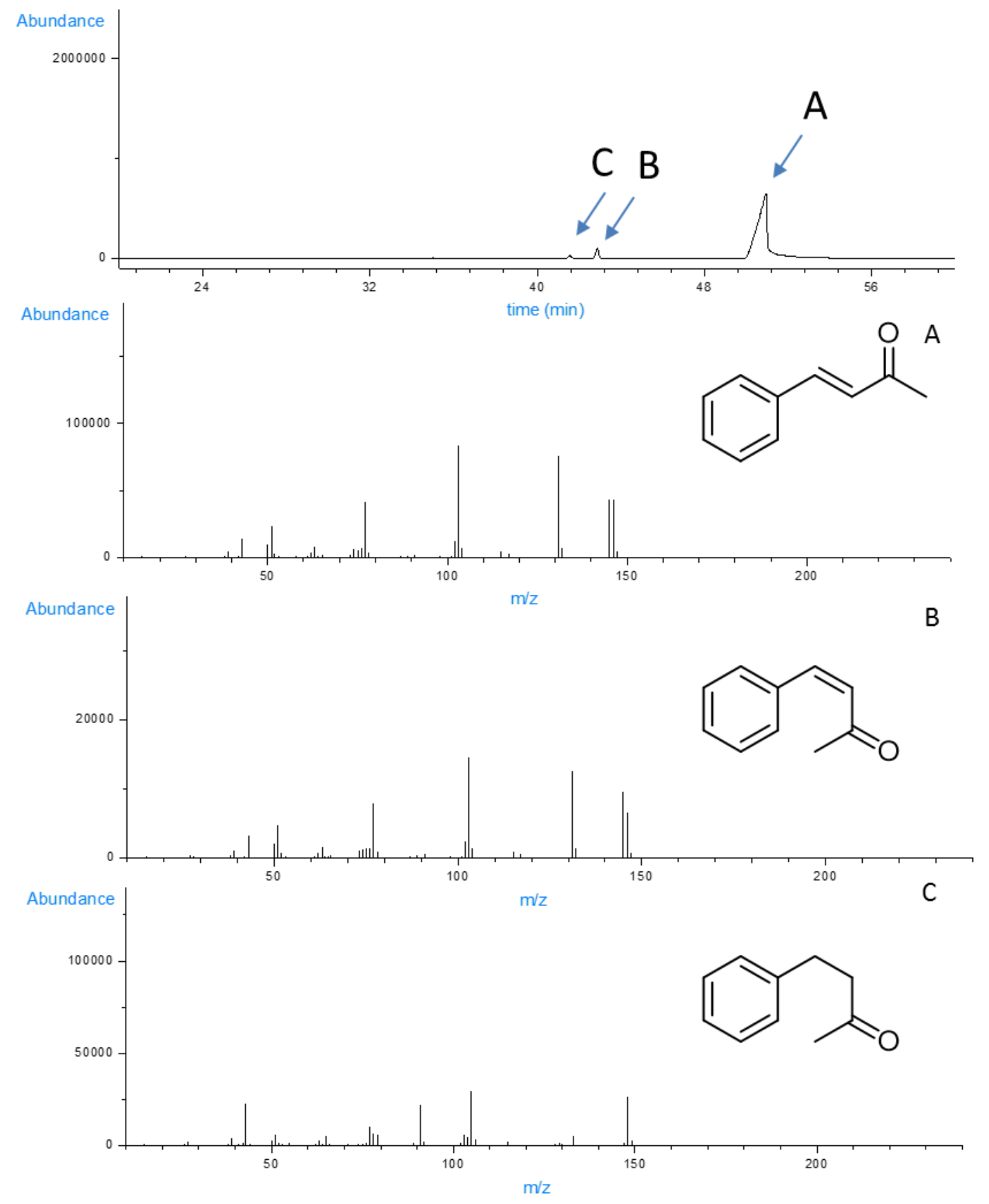

Figure S33. GC-MS data for the hydrogenation products of ketone functionalized alkyne to the corresponding trans-alkene using Rh-S/Pd NSs catalysts. 

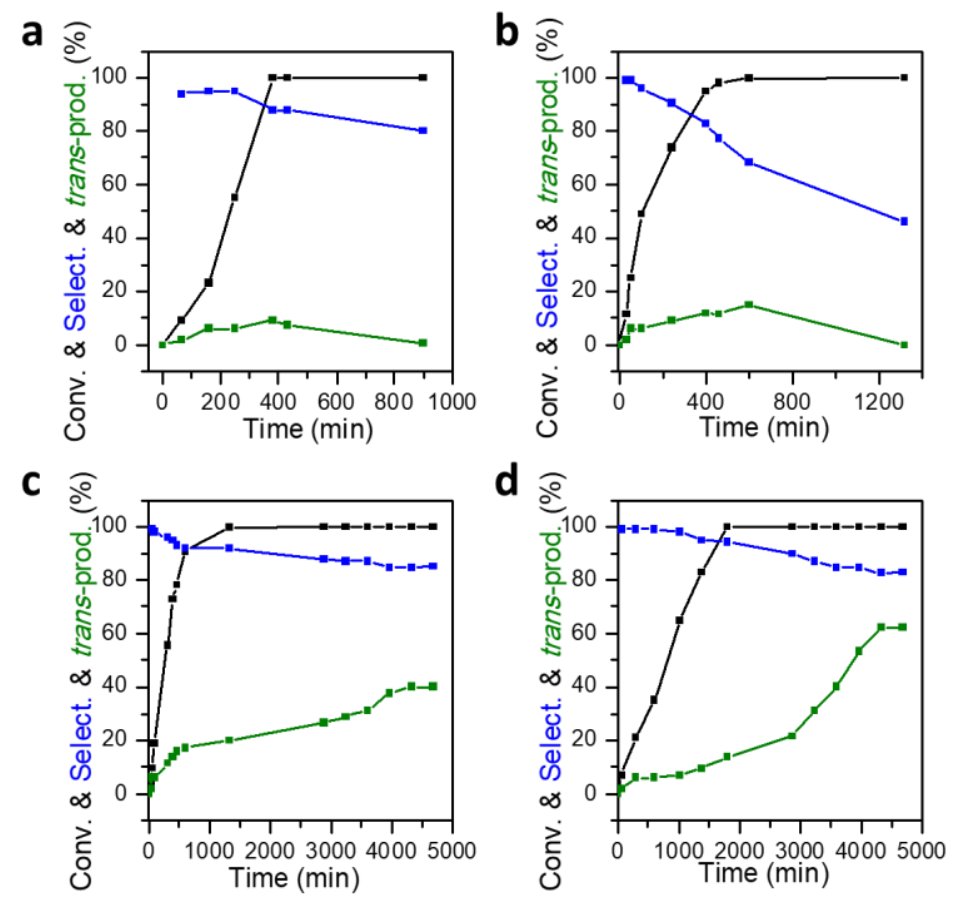

Figure S34. Hydrogenation of 1-phenyl-1-propyne to trans-product catalyzed by $\mathrm{RhS}_{\mathrm{x}} / \mathrm{Pd}$ NSs by varying the $\mathrm{Pd} / \mathrm{Rh}$ ratio of raw materials used in $\mathrm{Rh} / \mathrm{Pd}$ synthesis. $0.1: 1$ (a), 0.3:1 (b), 0.5:1 (c), and 1:1(d).

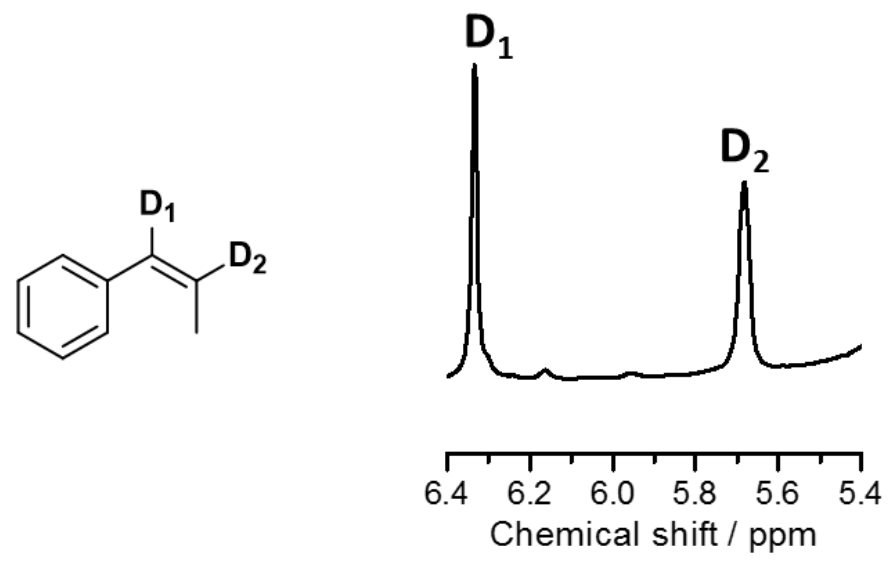

Figure S35. ${ }^{2} \mathrm{H}$ NMR for semi-hydrogenation of 1-phenyl-1-propyne carried out by using $\mathrm{Rh}-\mathrm{S} / \mathrm{Pd}$ as catalyst and $\mathrm{D}_{2}$. 

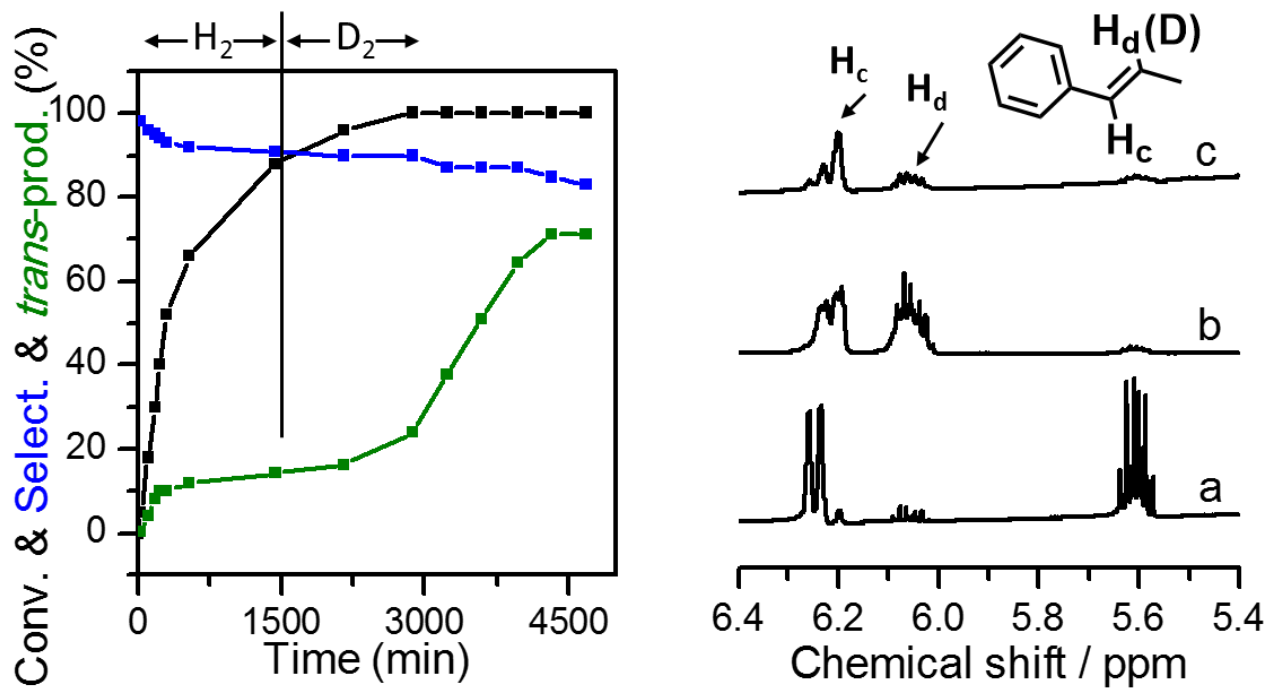

Figure S36. Schematic diagram of ${ }^{1} \mathrm{H}$ NMR data for semi-hydrogenation of 1-phenyl-1propyne carried out by using $\mathrm{Rh}-\mathrm{S} / \mathrm{Pd}$ as catalyst and $\mathrm{H}_{2}$ or $\mathrm{D}_{2}$ (a is the regular product at 1500 min under $\mathrm{H}_{2}, \mathrm{~b}$ is the final product under $\mathrm{H}_{2}, \mathrm{c}$ is the final product under $\mathrm{H}_{2}$ then switched to $\mathrm{D}_{2}$ ). 
Table S1 Catalytic performance of some reported works about the isomerization reaction.

\begin{tabular}{|c|c|c|c|c|c|c|c|c|c|c|c|}
\hline \multirow[b]{2}{*}{ Catalyst } & \multirow[b]{2}{*}{ Temp. } & \multirow[b]{2}{*}{ Solvent } & \multirow[b]{2}{*}{ H resource } & \multicolumn{4}{|c|}{ Substrate } & \multirow[b]{2}{*}{ Catalytic Performance } & \multirow[b]{2}{*}{ TOF $\left(h^{-1}\right)^{e}$} & \multirow[b]{2}{*}{ TOF $\left(h^{-1}\right)^{f}$} & \multirow[b]{2}{*}{ Ref. } \\
\hline & & & & $\mathrm{a}$ & $\mathrm{b}$ & $\mathrm{c}$ & $\mathrm{d}$ & & & & \\
\hline \multicolumn{12}{|l|}{ Homogeneous catalysis } \\
\hline $\mathrm{Cl}_{2} \mathrm{Pd}_{(}\left(\mathrm{PPh}_{3}\right)_{2}+\mathrm{ZnI}_{2}+\mathrm{Zn}$ & $25^{\circ} \mathrm{C}$ & THF & $\mathrm{H}_{2}(1 \mathrm{~atm})$ & - & + & - & - & $\begin{array}{l}\text { Conv }>99 \% \text {, Select } 90 \% \\
\text { E:Z 99:1 }\end{array}$ & 2.5 & 0.99 & 10 \\
\hline $\begin{array}{l}{\left[(\mathrm{HACRPNP}) \mathrm{Fe}\left(\mathrm{CH}_{3} \mathrm{CN}\right)\left(\mathrm{h}_{2^{-}}\right.\right.} \\
\left.\left.\mathrm{CH}_{3} \mathrm{CHCNBH}_{3}\right)\right]\end{array}$ & $90^{\circ} \mathrm{C}$ & THF & $\mathrm{H}_{2}(4 \mathrm{~atm})$ & - & + & - & - & $\begin{array}{l}\text { Conv }>99 \% \text {, Selectivity } 100 \% \\
\text { E:Z>95:5 }\end{array}$ & 13.9 (Table 2) & 1.8 (Table 2) & 11 \\
\hline (IMes)Ag-Rp & $150^{\circ} \mathrm{C}$ & xylenes & $\mathrm{H}_{2}(1 \mathrm{~atm})$ & - & + & - & + & $\begin{array}{l}\text { Conv }>90 \% \text {, Selectivity }>90 \% \\
\text { E:Z }>95: 5\end{array}$ & 0.20 (Table 2) & 0.19 (Table 3) & 12 \\
\hline$(\mathrm{MesCCC}) \mathrm{Co}\left(\mathrm{N}_{2}\right)\left(\mathrm{PPh}_{3}\right)$ & $30^{\circ} \mathrm{C}$ & THF & $\mathrm{H}_{2}(4 \mathrm{~atm})$ & - & + & - & - & $\begin{array}{l}\text { Conv } 79 \% \text {, Selectivity } 99 \% \\
\text { E:Z> 99:1 }\end{array}$ & 4.65 & - & 13 \\
\hline $\begin{array}{l}\mathrm{PdCl}_{2}(\mathrm{dppf}) / \mathrm{dppf} \\
\mathrm{CuSO}_{4}\end{array}$ & Reflux & toluene $/ \mathrm{H}_{2} \mathrm{O}=10 / 1$ & $\mathrm{HSiEt}_{3}$ & + & + & - & - & $\begin{array}{l}\text { Conv } 99 \% \text {, Selectivity } 99 \% \\
\text { E:Z > 99:1 }\end{array}$ & 0.55 (Table 2) & - & 14 \\
\hline$[\mathrm{Cp} * \mathrm{Ru}($ alkene $)]+$ & $20^{\circ} \mathrm{C}$ & methanol- $\mathrm{d}_{4}$ & $\mathrm{H}_{2}(1 \mathrm{~atm})$ & - & + & - & - & - & - & - & 15 \\
\hline$[\mathrm{Cp} * \mathrm{Ru}(\mathrm{cod}) \mathrm{Cl}]$ & r.t. & $\mathrm{CH}_{2} \mathrm{Cl}_{2}$ & $\mathrm{H}_{2}(10 \mathrm{~atm})$ & + & + & - & - & $\begin{array}{l}\text { Yield } 82 \%, \text { Selectivity } ~ 90 \% \\
E: Z>98: 2 \text { (Table 1) }\end{array}$ & 36 & - & 16 \\
\hline $\mathrm{Mo}_{3} \mathrm{~S}_{4}$ cluster & $150^{\circ} \mathrm{C}$ & $\mathrm{CH}_{3} \mathrm{CN}$ & $\mathrm{H}_{2}(100$ bar $)$ & - & + & - & - & $\begin{array}{l}\text { Yield } 65 \% \text {, Selectivity } 100 \% \\
\text { E:Z 85:15 (Table 1) }\end{array}$ & 1.11 & - & 17 \\
\hline $\mathrm{Pd}(\mathrm{OAc})_{2}, \mathrm{IPrCuOt}-\mathrm{Bu}$ & $45^{\circ} \mathrm{C}$ & Toluene $\mathrm{MeOH}$ & $\mathrm{Me}_{2} \mathrm{i}-\mathrm{PrSiH}$ & + & + & - & - & Yield $88 \%, E: Z$ 88:12 (Scheme 9) & $0.83^{\mathrm{g}}$ & & 18 \\
\hline $\mathrm{HB}\left(\mathrm{C}_{6} \mathrm{~F}_{5}\right)_{2}$ & $140^{\circ} \mathrm{C}$ & toluene & $\mathrm{H}_{2}(50$ bar $)$ & & + & - & - & $\begin{array}{l}\text { Conv } 99 \%, \text { Sel } 96 \% \\
E: Z>95: 5\end{array}$ & 1.6 (Table 2) & - & 19 \\
\hline
\end{tabular}




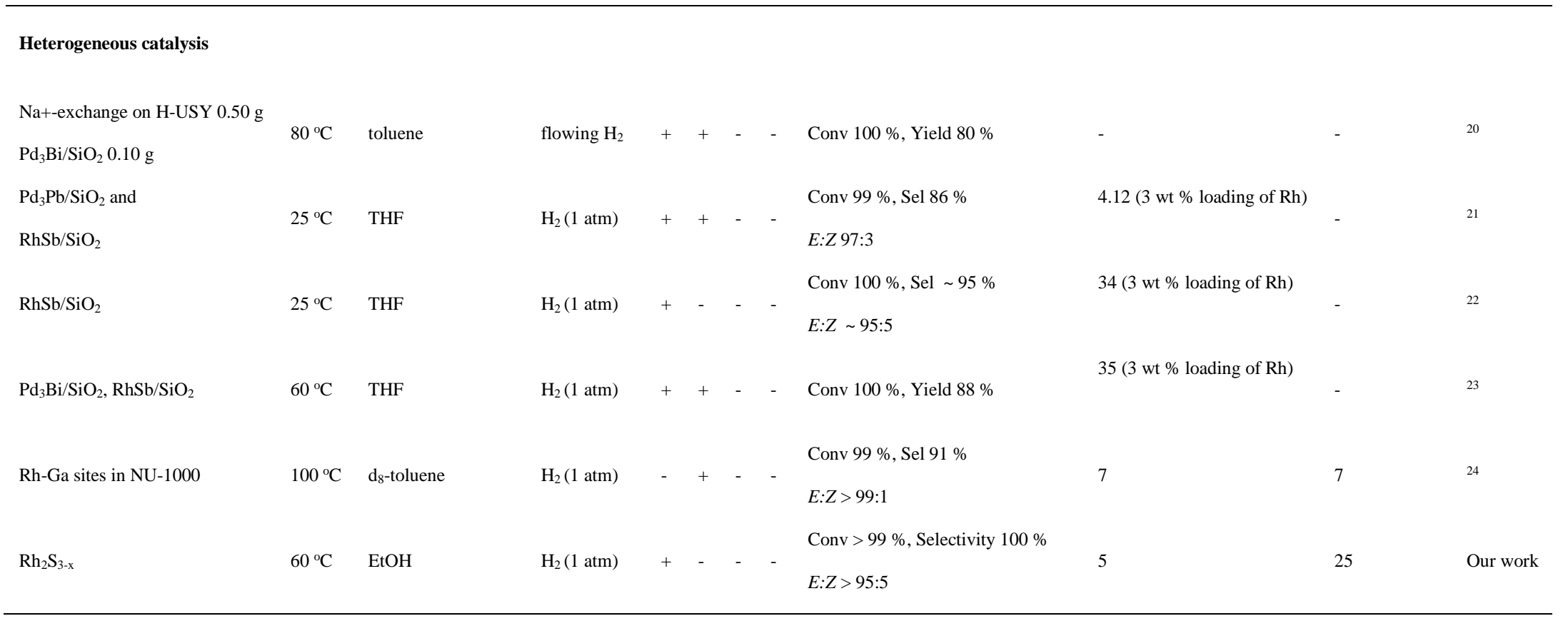

${ }^{\mathrm{a}}$ Internal Alkenes, ${ }^{\mathrm{b}}$ Internal Alkynes, ${ }^{\mathrm{c}}$ Terminal Alkenes, ${ }^{\mathrm{d}}$ Terminal Alkynes, ${ }^{\mathrm{e}}$ diphenylacetylene or Z-stilbene, ${ }^{\mathrm{f}}$ 1-Phenyl-1-propyne or Z-beta-Methylstyrene, ${ }^{\mathrm{g}}$ (1-methoxy-4$[(Z)$-2-(4-methoxyphenyl)ethenyl]benzene) 
Table S2. Structural parameters of the samples obtained by fitting the EXAFS.

\begin{tabular}{|c|c|c|c|c|c|c|}
\hline Sample & Path & C.N. & $\mathbf{R}(\AA)$ & $\sigma^{2} \times 10^{3}\left(\AA^{2}\right)$ & $\Delta E(e V)$ & $\mathbf{R}$ factor \\
\hline Pd foil & $\mathrm{Pd}-\mathrm{Pd}$ & $12 *$ & $2.74 \pm 0.002$ & $5.2 \pm 0.3$ & $1.3 \pm 0.4$ & 0.003 \\
\hline \multirow{3}{*}{$\mathbf{P d}$ in $\mathbf{R h}-\mathrm{S} / \mathbf{P d}$} & $\mathrm{Pd}-\mathrm{S}$ & $1.8 \pm 0.4$ & $2.28 \pm 0.02$ & $9.1 \pm 3.4$ & $-4.6 \pm 2.7$ & \multirow{3}{*}{0.001} \\
\hline & & & & & & \\
\hline & Pd-Pd & $6.5 \pm 0.2$ & $2.78 \pm 0.02$ & $7.7 \pm 0.3$ & $-3.9 \pm 0.3$ & \\
\hline \multirow{2}{*}{$\mathbf{R h}$ in $\mathbf{R h} / \mathbf{P d}$} & $\mathrm{Rh}-\mathrm{O}$ & $4.2 \pm 0.3$ & $2.03 \pm 0.01$ & $3.5 \pm 0.9$ & $-0.5 \pm 1.2$ & \multirow{2}{*}{0.005} \\
\hline & $\mathrm{Rh}-\mathrm{Rh} / \mathrm{Pd}$ & $0.8 \pm 0.6$ & $2.72 \pm 0.03$ & $5.8 \pm 4.4$ & $-11.9 \pm 5.2$ & \\
\hline \multirow{2}{*}{$\mathbf{R h}$ in $\mathbf{R h}-\mathbf{S} / \mathbf{P d}$} & $\mathrm{Rh}-\mathrm{S}$ & $3.3 \pm 0.5$ & $2.23 \pm 0.01$ & $8.1 \pm 1.7$ & $-11.8 \pm 2.4$ & \multirow{2}{*}{0.009} \\
\hline & $\mathrm{Rh}-\mathrm{Pd}$ & $3.6 \pm 1.2$ & $2.78 \pm 0.02$ & $12.8 \pm 3.1$ & $-4.4 \pm 2.2$ & \\
\hline
\end{tabular}

C.N.: coordination numbers; $R$ : bond distance; $\sigma^{2}$ : Debye-Waller factors; $\Delta E_{0}$ : the inner potential correction. $R$ factor: goodness of fit.

* The experimental EXAFS fit of metal foil by fixing $\mathrm{CN}$. The calculated amplitude $\left(\mathrm{S}_{0}^{2}=0.82\right)$ was used for Pd and Rh K edge EXAFS fitting. 


\section{References:}

1. Huang, X.; Tang, S.; Mu, X.; Dai, Y.; Chen, G.; Zhou, Z.; Ruan, F.; Yang, Z.; Zheng, N., Freestanding palladium nanosheets with plasmonic and catalytic properties. Nat. Nanotechnol. 2011, 6, 28-32.

2. Yoon, D.; Seo, B.; Lee, J.; Nam, K. S.; Kim, B.; Park, S.; Baik, H.; Hoon Joo, S.; Lee, K., Facet-controlled hollow $\mathrm{Rh}_{2} \mathrm{~S}_{3}$ hexagonal nanoprisms as highly active and structurally robust catalysts toward hydrogen evolution reaction. Energy Environ. Sci. 2016, 9, 850-856.

3. Kresse, G.; Furthmüller, J., Efficiency of ab-initio total energy calculations for metals and semiconductors using a plane-wave basis set. Comput. Mater. Sci. 1996, 6, 15-50.

4. Kresse, G.; Hafner, J., Ab initio molecular dynamics for open-shell transition metals. Phys. Rev. B 1993, 48, 13115-13118.

5. Kresse, G.; Hafner, J., Ab initio molecular-dynamics simulation of the liquid-metalamorphous-semiconductor transition in germanium. Phys. Rev. B 1994, 49, 14251-14269.

6. Perdew, J. P.; Burke, K.; Ernzerhof, M., Generalized gradient approximation made simple. Phys. Rev. Lett. 1996, 77, 3865-3868.

7. Blöchl, P. E.; Jepsen, O.; Andersen, O. K., Improved tetrahedron method for Brillouinzone integrations. Phys. Rev. B 1994, 49, 16223-16233.

8. Kresse, G.; Joubert, D., From ultrasoft pseudopotentials to the projector augmentedwave method. Phys. Rev. B 1999, 59, 1758-1775.

9. Qin, R.; Zhou, L.; Liu, P.; Gong, Y.; Liu, K.; Xu, C.; Zhao, Y.; Gu, L.; Fu, G.; Zheng, N., Alkali ions secure hydrides for catalytic hydrogenation. Nat. Catal. 2020, 3, 703-709.

10. Maazaoui, R.; Abderrahim, R.; Chemla, F.; Ferreira, F.; Perez-Luna, A.; Jackowski, O., Catalytic chemoselective and stereoselective semihydrogenation of alkynes to $E$ alkenes using the combination of Pd catalyst and $\mathrm{ZnI}_{2}$. Org. Lett. 2018, 20, 7544-7549.

11. Srimani, D.; Diskin-Posner, Y.; Ben-David, Y.; Milstein, D., Iron Pincer complex catalyzed, environmentally Benign, E-selective semi-hydrogenation of alkynes. Angew. Chem. Int. Ed. 2013, 52, 14131-14134.

12. Karunananda, M. K.; Mankad, N. P., E-selective semi-hydrogenation of alkynes by heterobimetallic catalysis. J. Am. Chem. Soc. 2015, 137, 14598-14601.

13. Tokmic, K.; Fout, A. R., Alkyne semihydrogenation with a well-defined nonclassical Co- $\mathrm{H}_{2}$ Catalyst: a $\mathrm{H}_{2}$ spin on isomerization and E-selectivity. J. Am. Chem. Soc. 2016, 138, 13700-13705.

14. Luo, F.; Pan, C.; Wang, W.; Ye, Z.; Cheng, J., Palladium-catalyzed reduction of alkynes employing $\mathrm{HSiEt}_{3}$ : stereoselective synthesis of trans- and cis-alkenes. Tetrahedron 2010, 66, 1399-1403.

15. Schleyer, D.; Niessen, H. G.; Bargon, J., In situ ${ }^{1}$ H-PHIP-NMR studies of the stereoselective hydrogenation of alkynes to $(E)$-alkenes catalyzed by a homogeneous $\left[\mathrm{Cp}^{*} \mathrm{Ru}\right]^{+}$catalyst. New J. Chem. 2001, 25, 423-426.

16. Radkowski, K.; Sundararaju, B.; Fürstner, A., A functional-group-tolerant catalytictrans hydrogenation of alkynes. Angew. Chem. Int. Ed. 2013, 52, 355-360.

17. Algarra, A. G.; Guillamón, E.; Andrés, J.; Fernández-Trujillo, M. J.; Pedrajas, E.; Pino-Chamorro, J. Á.; Llusar, R.; Basallote, M. G., Cuboidal $\mathrm{Mo}_{3} \mathrm{~S}_{4}$ clusters as a platform for exploring catalysis: a three-center sulfur mechanism for alkyne semihydrogenation. ACS Catal. 2018, 8, 7346-7350. 
18. Armstrong, M. K.; Goodstein, M. B.; Lalic, G., Diastereodivergent reductive cross coupling of alkynes through tandem catalysis: $Z$ - and $E$-Selective hydroarylation of terminal alkynes. J. Am. Chem. Soc. 2018, 140, 10233-10241.

19. Liu, Y.; Hu, L.; Chen, H.; Du, H., An alkene-promoted borane-catalyzed highly stereoselective hydrogenation of alkynes to give Z- and E-Alkenes. Chem. Eur. J. 2015, $21,3495-3501$.

20. Komatsu, T.; Takagi, K.; Ozawa, K.-i., Synthesis of trans-stilbene through the hydrogenation of diphenylacetylene. Catal. Today 2011, 164, 143-147.

21. Furukawa, S.; Komatsu, T., Selective hydrogenation of functionalized alkynes to (E)alkenes, using ordered alloys as catalysts. ACS Catal. 2016, 6, 2121-2125.

22. Furukawa, S.; Ochi, K.; Luo, H.; Miyazaki, M.; Komatsu, T., Selective stereochemical catalysis controlled by specific atomic arrangement of ordered alloys. ChemCatChem 2015, 7, 3472-3479.

23. Furukawa, S.; Yokoyama, A.; Komatsu, T., Efficient catalytic system for synthesis of trans-stilbene from diphenylacetylene using Rh-based intermetallic compounds. ACS Catal. 2014, 4, 3581-3585.

24. Desai, S. P.; Ye, J.; Zheng, J.; Ferrandon, M. S.; Webber, T. E.; Platero-Prats, A. E.; Duan, J.; Garcia-Holley, P.; Camaioni, D. M.; Chapman, K. W.; Delferro, M.; Farha, O. K.; Fulton, J. L.; Gagliardi, L.; Lercher, J. A.; Penn, R. L.; Stein, A.; Lu, C. C., WellDefined Rhodium-Gallium Catalytic Sites in a Metal-Organic Framework: PromoterControlled Selectivity in Alkyne Semihydrogenation to E-Alkenes. J. Am. Chem. Soc. 2018, $140,15309-15318$. 